\title{
Transparent p-Type Semiconductors: Copper-Based Oxides and Oxychalcogenides
}

\author{
Nengduo Zhang ${ }^{1,2,+}$, Jian Sun ${ }^{3,+}$ and Hao Gong $1, * \mathbb{C}$ \\ 1 Department of Materials Science and Engineering, National University of Singapore, Singapore 117576, \\ Singapore; e0011485@u.nus.edu \\ 2 NUS Graduate School for Integrative Sciences and Engineering, National University of Singapore, \\ Singapore 117456, Singapore \\ 3 Faculty of Materials Science and Chemistry, China University of Geoscience, Wuhan 430074, China; \\ sunjian@cug.edu.cn \\ * Correspondence: msegongh@nus.edu.sg \\ + These authors contributed equally to this work.
}

Received: 31 January 2019; Accepted: 16 February 2019; Published: 20 February 2019

\begin{abstract}
While p-type transparent conducting materials (TCMs) are crucial for many optoelectronic applications, their performance is still not satisfactory. This has impeded the development of many devices such as photovoltaics, sensors, and transparent electronics. Among the various p-type TCMs proposed so far, $\mathrm{Cu}$-based oxides and oxychalcogenides have demonstrated promising results in terms of their optical and electrical properties. Hence, they are the focus of this current review. Their basic material properties, including their crystal structures, conduction mechanisms, and electronic structures will be covered, as well as their device applications. Also, the development of performance enhancement strategies including doping/co-doping, annealing, and other innovative ways to improve conductivity will be discussed in detail.
\end{abstract}

Keywords: p-type semiconductors; transparent oxides; delafossite; oxychalcogenide

\section{Introduction}

Transparent conducting oxides (TCOs) possess high electrical conductivity and good optical transparency in the visible light range, and they have been intensively studied over the past few decades due to their important roles in electronic industries including photovoltaic cells (PV cells), touch screen displays, solid-state sensors, organic light-emitting diodes (OLEDs), and liquid crystal displays [1-3]. Currently, in the electronics industry, many different materials, especially impurity-doped materials, are used as TCOs for the applications. Three major materials are $\operatorname{In}_{2} \mathrm{O}_{3}$ doped with $\mathrm{Sn}$ (ITO), $\mathrm{ZnO}$ doped with $\mathrm{Al}(\mathrm{AZO})$, Fluor tin oxide or $\mathrm{SnO}_{2}-\mathrm{F}$ (FTO), and $\mathrm{SnO}_{2}$ doped with Sb (ATO) [4,5], Among them, ITO, with its great electrical conductivity around $1000 \mathrm{~S} \cdot \mathrm{cm}^{-1}$ and optical transparency greater than $80 \%$, has a market share higher than $97 \%$ [6,7].

However, the aforementioned materials all belong to n-type TCOs, which show n-type conductivity. The popularity of n-type TCOs arises from their preferable electronic properties [8]. For n-type TCOs, the electrons as charge carriers move in the conduction band minimum (CBM). The CBM is largely formed by the spatially spread metal-s orbitals, resulting in a well-dispersed CBM and high electron mobility. In addition, the low formation energy of native intrinsic defects induces a high electron concentration and stable n-type electrical conductivity after impurity doping [9]. On the contrary, the development of high-performance p-type TCOs is very challenging [10,11], and it remains a grand challenge for researchers to solve. Indeed, it is very difficult to find p-type TCO with high conductivity due to the inherent low mobility of holes in the oxides. As can be seen in Figure 1, 
the effective mass of a hole is relatively higher than that of an electron [12]. This is caused by the valence band maximum (VBM) for hole transport being mainly formed by highly localized oxygen $2 p$ orbitals, leading to low hole mobility. Moreover, the low formation energy of intrinsic donor defect and relatively high acceptor formation energy limit the number of hole carriers [11].

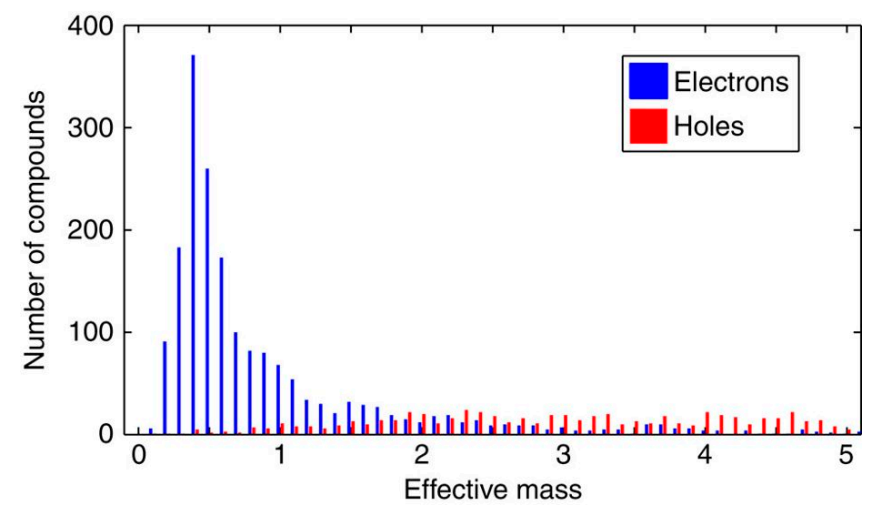

Figure 1. Effective mass distribution of both electrons and holes in selected binary and ternary oxides. Reproduced with permission from Ref. [12]. Copyright 2013 Springer Nature.

On the other hand, p-type TCOs are extremely important in many applications. For example, a p-type TCO, with its larger work function than its n-type counterpart, is more suitable for OLED devices $[13,14]$. However, with performance sacrifice, many of the current OLED applications use ITO as the transparent electrode instead of a p-type anode material due to the lack of high-performance p-type TCO $[13,14]$. In the perovskite solar cells, a hole transport layer (HTL) usually is made of the popular semi-metallic organic material poly(3,4-ethylenedioxythiophene):poly(styrenesulfonate) (PEDOT:PSS), and this has been shown to negatively affect the stability of the device, which is a serious issue for perovskite solar cells [15-18]. Moreover, in the field of transparent electronics, wide gap oxides are no longer passive components in the device. Instead, transparent oxides play an essential role as active layers, similar to $\mathrm{Si}$ in current semiconductor industry. After achieving high-performance p-type TCOs, transparent $\mathrm{p}-\mathrm{n}$ junctions and a complementary metal oxide semiconductor (CMOS) could be fabricated for various applications with many more advantages than its unipolar transistors such as lower heat generation, higher circuit density, and lower energy consumption [19-21]. It is also believed that transparent electronics will become one of the most promising technologies for next-generation flat panel display [22], and the forecast shows that the transparent display would help create a $\$ 87.2$ billion market by 2025 , as can be seen in Figure 2 [2].

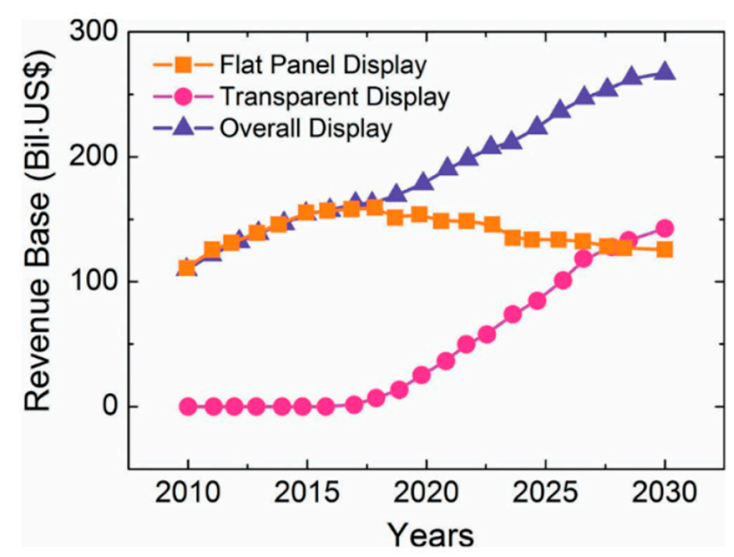

Figure 2. Transparent display market. Reproduced with permission from Ref. [2]. Copyright 2012 Wiley. 
In order for p-type TCOs to achieve reasonable electrical properties, in 1997, Kawazoe et al. introduced a concept called "Chemical Modulation of the Valence Band" (CMVB), as a way to deal with the aforementioned problem [23,24]. The delafossite structured $\mathrm{CuAlO}_{2}$ was prepared and discussed in that work. In delafossites, $\mathrm{Cu}^{+}$has a closed shell of $3 d^{10}$ orbitals which would hybridize with $\mathrm{O} 2 p$ orbitals and modify the VBM and make the hole more delocalized so that it increases the hole mobility [25]. This hybridization is possible because the energy level of $\mathrm{Cu} 3 d^{10}$ is close to that of $\mathrm{O} 2 p$. Subsequently, several other types of delafossites with the structure $\mathrm{CuMO}_{2}(\mathrm{M}=\mathrm{Al}$ [26-28], $\mathrm{Cr}$ [29-31], Ga [32-34], In [35-37], Sc [38-40], Y [41-43], Fe [44-46], and B [47-49]) and delafossite-related oxide $\mathrm{SrCu}_{2} \mathrm{O}_{2}$ [50-52] have been investigated. In 2001, the delafossite with a rather high p-type conductivity of $220 \mathrm{~S} \cdot \mathrm{cm}^{-1}$ was achieved by $\mathrm{Mg}$-doped $\mathrm{CuCrO}_{2}$, but the transparency is not satisfying [30]. Many of these delafossites have been used in the applications such as OLEDs as a hole injection layer (HIL) or hole transport layer (HTL) due to their suitable work function, good stability, and preferable electronic properties $[53,54]$. While a lot of attention has been paid to such p-type TCOs, it seems very challenging for delafossites to attain the high conductivity and high transparency that would make them comparable to current n-type TCOs [55]. The rather low conductivity is caused by their deep acceptor level [56], and polaronic nature [43,57]. In some cases, the transparency of a delafossite is limited by the interband transitions [58]. The band-engineering CMVB technique was later used on other $\mathrm{Cu}^{+}$-based materials, especially materials with chalcogens such $\mathrm{Cu}_{2} \mathrm{~S}, \mathrm{Cu}_{2} \mathrm{Se}$, and $\mathrm{Cu}_{2} \mathrm{Te}$ [59]. Even though chalcogen-based TCOs have greater hole mobility due to their stronger hybridization with $\mathrm{Cu} 3 d$ states by the chalcogens than oxygen [10], they suffer greatly from their narrow band gap, which limits their visible light transparency [60]. Therefore, it appears that a high-performance TCO should include oxygen for a large band gap and chalcogen for a high hole mobility. Subsequently, layered oxychalcogenides have been developed to demonstrate a large band gap and high hole mobility due to the hybridization of $\mathrm{Cu}$ and chalcogens. Layered oxychalcogenide has alternate layers of [ $\mathrm{LnO}]^{+}$ ( $\mathrm{Ln}=\mathrm{La}, \mathrm{Y}, \mathrm{Pr}$, etc.) and $[\mathrm{CuCh}]^{-}\left(\mathrm{Ch}=\mathrm{S}, \mathrm{Se}, \mathrm{Te}\right.$, etc.), in which the $[\mathrm{CuCh}]^{-}$is essential for its p-type conductivity and band gap [61,62]. It has been reported that the conduction band minimum (CBM) and the valence band maximum (VBM) comprise a $\mathrm{Cu}-\mathrm{Ch}$ hybridized band and $\mathrm{Cu}-\mathrm{Ch}$ anti-bonding band, respectively $[13,63]$. This forms a direct band gap that allows a direct transition of charge carriers, which is more useful in applications than indirect band-gap materials $[10,62,63]$. While oxychalcogenides have promising properties that enable them to be used as future transparent p-type materials, their hole mobility is around $10^{0} \mathrm{~cm}^{2} \cdot \mathrm{V}^{-1} \cdot \mathrm{s}^{-1}$ or less. For applications such as thin-film transistors (TFTs), which require materials with high mobility, cuprous oxide $\left(\mathrm{Cu}_{2} \mathrm{O}\right)$, with its high hole mobility greater than $2.0 \times 10^{2} \mathrm{~cm}^{2} \cdot \mathrm{V}^{-1} \cdot \mathrm{s}^{-1}$, seems more suitable [64], even though it has a small band gap $(2.0-2.5 \mathrm{eV})$ that is only transparent for part of the visible light range [65-67]. The high mobility of $\mathrm{Cu}_{2} \mathrm{O}$ originates from the rather delocalized VBM, which is formed mainly by $\mathrm{Cu} d$ states, and the VB is formed by the hybridization of $\mathrm{O} 2 p$ and $\mathrm{Cu} 3 d$ orbitals $[68,69]$. In this review, we will focus on the discussion of three types of materials, including delafossites, oxychalcogenides, and copper oxides.

\section{Preparation and Properties of Materials}

\subsection{Delafossite $\left(\mathrm{CuMO}_{2}\right)$}

Before the realization of $\mathrm{CuAlO}_{2}$ delafossite (band gap $>3 \mathrm{eV}$ ) as a transparent p-type oxide [24], p-type conductivity in oxides with large band gaps was too low to be used in any industrial applications. As briefly mentioned above in the introduction, the low electrical conductivity is the result of the general electronic structure in the metal oxides. This is because oxygen $2 p$ orbitals are generally at a much lower energy level than that of the metallic atoms in ionic metal oxides, leading to a highly localized and deep valence band that is formed by oxygen $2 p$ orbitals. Holes generated in the oxides would be attracted and localized by oxygen ions, leading to very low hole mobility $[8,23]$. To tackle the problem of low hole mobility, the highly localized VB or VBM need to be modified to be more dispersed. To achieve such band modification, a design strategy named "Chemical Modulation of 
the Valence Band" (CMVB) was proposed in 1997 [23,24]. The cation selected by this strategy should possess the electronic configuration such that its highest shell electrons should be situated at similar energy levels as that of oxygen $2 p$ orbitals. As shown in Figure 3a, this would introduce chemical bonds and make the newly formed VB or VBM more spatially dispersed. In addition, the selected cation should also have a closed shell valence state to prevent coloration in the transparent oxides caused by $\mathrm{d}-\mathrm{d}$ transitions. After carefully selecting the right cations, it was found that both $\mathrm{Cu}^{+}$and $\mathrm{Ag}^{+}$possess suitable electronic configuration of $d^{10} s^{0}$, and they are at a similar energy level as that of oxygen $2 p$ orbitals [23]. When $\mathrm{Cu}^{+}$or $\mathrm{Ag}^{+}$cations are brought to oxygen ions, chemical bonds with a certain degree of covalency would be formed, and the VBM would be formed by the anti-bonding levels of the resulting band formation (as can be observed in Figure 3a). Besides the overlap of the orbitals to create dispersed VBs or VBMs, the crystal structure is also important for the transparent oxide performance for two reasons. Firstly, the tetrahedral coordination of oxygen would ensure all eight of its electrons were involved in the four sigma bonds, as can be seen in Figure $3 b$ [70]. As the non-bonded electrons that are normally present in oxides would result in the generated holes having low mobility, the absence of non-bonded electrons of oxygen would lead to a higher hole mobility. Secondly, the crystal structure of the delafossite is also advantageous to its optical properties. For the prototypical delafossite $\mathrm{CuAlO}_{2}$, it has a layered structure with two alternating arrays comprising of $\mathrm{Cu}$ and the edge-sharing distorted $\mathrm{MO}_{6}$ octahedral unit along the vertical axis, and the two layers are connected by the $\mathrm{O}-\mathrm{Cu}-\mathrm{O}$ bonds [43]. This reduces the cross-linking between $\mathrm{Cu}^{+}$as compared to that in $\mathrm{Cu}_{2} \mathrm{O}$, which would decrease the interaction between the $d^{10}$ electrons of $\mathrm{Cu}^{+}$ions. Since it has been reported that such $d^{10}$ electrons interaction between neighboring atoms would decrease the band gap such as the case in $\mathrm{Cu}_{2} \mathrm{O}$ where interaction among three-dimensional $3 d^{10}$ electrons is present, the layered delafossite would improve the optical transparency [11,24]. Therefore, the delafossite based on $\mathrm{Cu}^{+}$has been predicted to be a potential high performance candidate for p-type TCOs in terms of its electrical and optical properties. In addition, the doping of divalent atoms at the site of trivalent metal $\mathrm{M}$ is believed to greatly enhance the p-type conductivity of delafossites [11], even though the effect of size of the trivalent metal atom on the conductivity trend still remains under intense debate [30,71]. It should be noted that even though both $\mathrm{Cu}^{+}$and $\mathrm{Ag}^{+}$have a suitable electronic configuration of $d^{10} s^{0}, \mathrm{Cu}^{+}$-based delafossites are usually preferred due to the following two reasons [49]. Firstly, Ag-based delafossites are difficult to be synthesized partially due to the low free energy of forming $\mathrm{Ag}_{2} \mathrm{O}$, and decomposition will occur at $300^{\circ} \mathrm{C}$ into $\mathrm{O}$ and $\mathrm{Ag}$ [72]. Secondly, it was shown experimentally that Ag-based delafossites exhibit lower conductivity compared to Cu-based delafossites due to unfavorable mixing between the $\mathrm{Ag} 4 d$ and $\mathrm{O} 2 p$ states [71,73-75].

Delafossites with the formula $\mathrm{CuMO}_{2}$ have two polytypes, namely a rhombohedral 3R and hexagonal $2 \mathrm{H}$ type, depending on the stacking sequence of the $\mathrm{Cu}$ and double layer $\mathrm{MO}_{2}$. For the rhombohedral 3R type, the alternative $\mathrm{Cu}$ layer has the same orientation between each $\mathrm{MO}_{2}$ layer within three layers, and each unit cell has three layers with the space group R $\overline{3} \mathrm{~m}$ (No. 166) (Figure $3 \mathrm{~b}$ ). For the hexagonal $2 \mathrm{H}$ type, each unit cell contains two layers with $\mathrm{MO}_{2}$ and $\mathrm{Cu}$ layers with $180^{\circ}$ offset for each alternating $\mathrm{Cu}$ layer with the space group $\mathrm{P}_{3} / \mathrm{mmc}$ (No. 194) (Figure 3c). It has been reported that certain delafossites such as $\mathrm{CuAlO}_{2}, \mathrm{CuGaO}_{2}$, and $\mathrm{CuInO}_{2}$ generally prefer the rhombohedral 3R type, while other delafossites such as $\mathrm{CuScO}_{2}, \mathrm{CuYO}_{2}$, and $\mathrm{CuLaO}_{2}$ normally adopt a hexagonal $2 \mathrm{H}$ form [76]. In addition, the former type of delafossite has an indirect band gap, and the many latter ones possess a direct band gap $[43,77,78]$. It should be noted that the relative energy difference between the two polytypes is generally rather small $[79,80]$, so the relative phase stability for each delafossite is still under debate [81]. Different synthesis routes and preparation conditions might result in different symmetries, and it is not uncommon to find the prepared delafossite with a mixture of both $3 \mathrm{R}$ and $2 \mathrm{H}$ polymorphs [82-84]. So far, most of the delafossites that have been used for p-type TCO applications are reported to possess rhombohedral 3R structures [49,81,85-87]. 
(a)

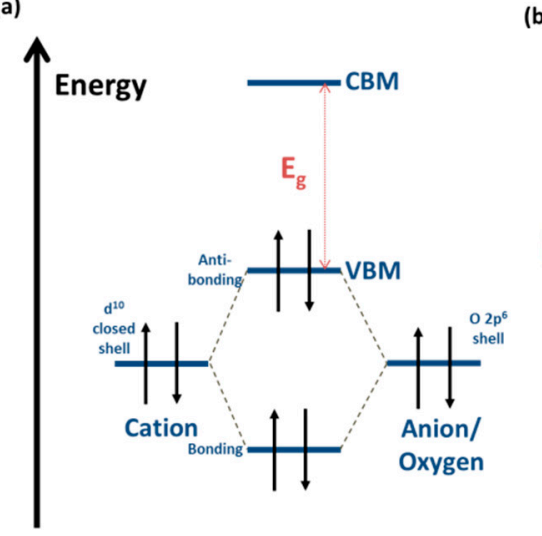

(b)

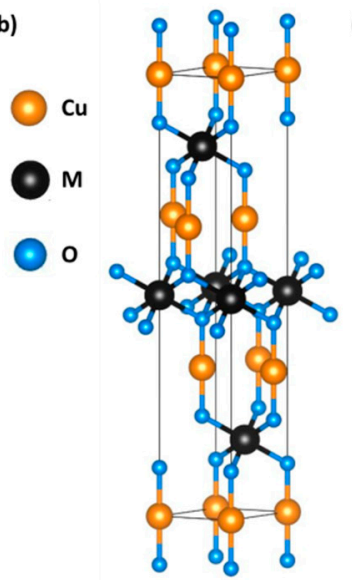

(c)

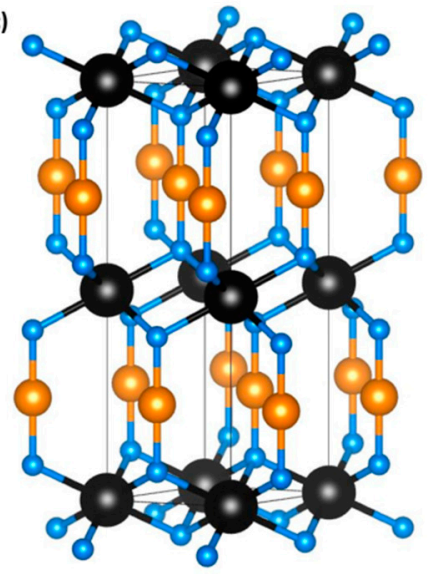

Figure 3. (a) Schematic diagram of the interaction between cation with a $d^{10}$ closed shell and oxygen anion, the anti-bonding formed by the hybridization give the valence band maximum (VBM) of the delafossites. Crystal structure of the delafossite of $(\mathbf{b})$ rhombohedral 3R type and (c) hexagonal 2H type.

As mentioned above, $\mathrm{CuAlO}_{2}$ is the first material in the delafossite family to be prepared as a p-type transparent oxide back in 1997 [24], even though $\mathrm{CuAlO}_{2}$ was already illustrated to possess p-type conductivity in 1984 [88]. Since its first introduction as a promising p-type TCO, a lot of research effort has been put on the development of delafossites with good electrical and optical properties. Since 1997, many thin film fabrication methods have been used to prepare transparent p-type $\mathrm{CuMO}_{2}$ films, including vacuum-based routes such as radio-frequency magnetron sputtering (RFMS) [89,90], pulsed laser deposition (PLD) [32,91], chemical vapor deposition (CVD) [26,29], atomic layer deposition (ALD) $[92,93]$ and non-vacuum based routes such as the hydrothermal/solvothermal method [94,95], sol-gel process [27,96], the spin-coating method [97,98], and the spray-coating method $[99,100]$. Each thin film fabrication method has its own advantages. For example, RFMS is relatively cost-efficient among all the vacuum-based methods, and is compatible with industrial applications for large scalability [101,102]; PLD is better at conserving the stoichiometry ratio in the target and producing high-quality epitaxy thin films [103-105]; and ALD has good control of both elemental composition and thin film morphology $[106,107]$. While many high-performance delafossites have been prepared via these state-of-art vacuum-based approaches, the chemical solution-based method has attracted more and more research attention recently, as it allows for low-cost fabrication, roll-to-roll capability, low-temperature synthesis, high throughput, and the possibility for special nanostructures [108-110]. Today, the above-mentioned thin film approaches are used in various research groups to prepare $\mathrm{CuMO}_{2}$, as discussed briefly below. The electrical and optical properties of the selected high-performance delafossites are tabulated in Table 1.

$\mathrm{CuAlO}_{2}$ was firstly prepared as a transparent p-type oxide in 1997 by using PLD at a substrate temperature of $700{ }^{\circ} \mathrm{C}$ [24]. The deposited thin film of $500 \mathrm{~nm}$ belongs to the rhombohedral 3R type, and it has a p-type conductivity of around $1 \mathrm{~S} \cdot \mathrm{cm}^{-1}$ and an optical band gap of $3.5 \mathrm{eV}$ with a poor transmittance around 30\% [24]. After this, the same group investigated the electronic properties of $\mathrm{CuAlO}_{2}$ in more detail, and they obtained thin film with conductivity around $0.3 \mathrm{~S} \cdot \mathrm{cm}^{-1}$ and transparency of $70 \%$ via the PLD approach [111]. It should be noted that the delafossite $\mathrm{CuMO}_{2}$ phase is not trivial to achieve due to the unstable oxidation state of $\mathrm{Cu}^{+}$and the complex phase diagram of $\mathrm{Cu}$, $\mathrm{M}$, and $\mathrm{O}$ [112]. Later studies has been carried out to achieve phase-pure $\mathrm{CuAlO}_{2}$, in order to eliminate common impurities such as $\mathrm{CuAl}_{2} \mathrm{O}_{4}$ and $\mathrm{CuO}$ [91]. In 2000, Gong et al. developed a $\mathrm{Cu}-\mathrm{Al}-\mathrm{O}-$ based semiconductor thin film via the CVD method that is industrial compatible, and the p-type conductivity is as high as $2 \mathrm{~S} \cdot \mathrm{cm}^{-1}$ [26]. As an attempt to further improve the electrical conductivity of intrinsic $\mathrm{CuAlO}_{2}$, high-quality nanocrystalline oxide particles were prepared via the hydrothermal method, and the deposited thin film possesses a conductivity of $2.4 \mathrm{~S} \cdot \mathrm{cm}^{-1}$ with a transparency at the 550-nm wavelength around 55\% [94]. Similar to other semiconducting oxides, doping is usually an effective 
way to increase electrical conductivity. Various theoretical studies has been carried out on delafossite $\mathrm{CuAlO}_{2}$ to study its doping possibility, and Group II (alkaline earth) elements were suggested as suitable dopants $[113,114]$. Detailed experimental evidence was shown by Dong et al., where $2 \%$ $\mathrm{Mg}$ improves the $\mathrm{CuAlO}_{2}$ by three orders, although the final conductivity is only $0.083 \mathrm{~S} \cdot \mathrm{cm}^{-1}$ [115]. Besides the hard work to improve the optoelectronic properties, the conducting mechanism and material physics were examined by both experiments and theoretical studies [87,116]. It has been shown that the close-packed $\mathrm{Cu}^{+}$alternative layers act as the hole transport path [117]. Due to its anisotropic structural properties, the ab-planes have a hole mobility that is 25 times lower than the c-axis, where the mobility along the c-axis is around $3.0 \mathrm{~cm}^{2} \cdot \mathrm{V}^{-1} \cdot \mathrm{s}^{-1}$ [118]. The p-type conductivity of $\mathrm{CuAlO}_{2}$ was proven to be originated from the $\mathrm{Cu}$ vacancies and $\mathrm{Cu}$ on $\mathrm{Al}$ antisites in the oxides, which have a rather small formation energy, and $\mathrm{Cu}$ vacancy is a shallow-level defect with an ionization energy of $0.7 \mathrm{eV}[87,89,118]$. In contrast, $\mathrm{O}$ interstitials were found to be not responsible for the p-type conductivity, as they are deep-level defects and relatively unstable $[87,119]$. In addition, it was generally believed that the conduction mechanism for $\mathrm{CuAlO}_{2}$ and other delafossites is via an activated small polaronic hopping mechanism, in which distorted lattice and trapped holes interact and move between $\mathrm{Cu}$ sites, leading to relatively low hole mobility $[43,57,87,116]$. In order to achieve a higher hole mobility of p-type conductivity, Yao et al. recently used an innovative way to enhance the hole mobility of $\mathrm{CuAlO}_{2}$ with an ultra-high Hall mobility of $39.5 \mathrm{~cm}^{2} \cdot \mathrm{V}^{-1} \cdot \mathrm{s}^{-1}$ [120]. Polycrystalline $\mathrm{CuAlO}_{2}$ deposited on the Si substrate via RFMS was incorporated with different amount of non-isovalent $\mathrm{CuO}$. The atomic ratio of $\mathrm{Cu}^{2+} / \mathrm{Cu}^{+}$is varied, from $4.2 \%$ and $9.3 \%$, to $22.8 \%$, and the optical band gaps were changed from $3.79 \mathrm{eV}$ and $3.72 \mathrm{eV}$ to $3.46 \mathrm{eV}$, respectively. The high mobility achieved is found to be caused by the hybridization of $\mathrm{Cu}-\mathrm{O}$ dimers in the $\mathrm{CuAlO}_{2}$ lattice. The $\mathrm{Cu}-\mathrm{O}$ dimers have a VBM of $0.6 \mathrm{eV}$, which is higher than that of $\mathrm{CuAlO}_{2}$, so it would raise the $\mathrm{VBM}$ of the alloyed $\mathrm{CuAlO}_{2} / \mathrm{CuO}$. Moreover, the more diverse VBM of $\mathrm{CuO}$, which was formed mainly by $\mathrm{Cu}^{2+} 3 d^{9}$ bands, would modulate the $\mathrm{VBM}$ of $\mathrm{CuAlO}_{2} / \mathrm{CuO}$ and make it more delocalized, leading to a high hole mobility. Indeed, the top gate TFT made by this alloyed $\mathrm{CuAlO}_{2} / \mathrm{CuO}$ achieved good device performance with a high field effect mobility of $0.97 \mathrm{~cm}^{2} \cdot \mathrm{V}^{-1} \cdot \mathrm{s}^{-1}$, and the schematic drawing of the TFT device with its detailed device performance is shown in Figure 4 [120].

Table 1. Summary of selected delafossites with their material properties including thickness $(d)$, conductivity $(\sigma)$, transmittance $(T)$, and optical band gap $\left(E_{\mathrm{g}}\right)$. ALD: atomic layer deposition, CVD: chemical vapor deposition; PLD: pulsed laser deposition; RFMS: radio-frequency magnetron sputtering.

\begin{tabular}{ccccccc}
\hline Delafossites & Fabrication & $\boldsymbol{d} \mathbf{( n m )}$ & $\boldsymbol{\sigma} \mathbf{( S \cdot \mathbf { c m } ^ { - \mathbf { 1 } } )}$ & $\boldsymbol{T} \mathbf{( \% )}$ & $\boldsymbol{E}_{\mathbf{g}} \mathbf{( e V )}$ & Ref. \\
\hline $\mathrm{CuAlO}_{2}$ & PLD & 230 & 0.3 & 70 & 3.50 & {$[111]$} \\
$\mathrm{CuAlO}_{2}$ & Hydrothermal & 420 & 2.4 & 55 & 3.75 & {$[94]$} \\
$\mathrm{CuAlO}_{2}$ & RFMS & - & $2.7 \times 10^{-2}$ & - & 3.79 & {$[120]$} \\
$\mathrm{CuScO} 2$ & RFMS & 110 & 30 & 40 & 3.30 & {$[38]$} \\
$\mathrm{CuCrO}_{2}: \mathrm{Mg}$ & RFMS & 250 & 220 & 30 & 3.10 & {$[30]$} \\
$\mathrm{CuCrO}_{2}: \mathrm{Mg}$ & ALD & 120 & 217 & 70 & 3.00 & {$[93]$} \\
$\mathrm{CuCrO}_{2}: \mathrm{Mg}$ & Spray coating & 155 & 1 & 80 & 3.08 & {$[121]$} \\
$\mathrm{CuCrO}_{2}: \mathrm{Zn}$ & Sol-gel & 205 & 0.47 & 55 & 3.05 & {$[122]$} \\
$\mathrm{CuCrO}_{2}: \mathrm{N}$ & RFMS & 290 & 17 & 55 & 3.19 & {$[123]$} \\
$\mathrm{CuCrO}_{2}: \mathrm{Mg} / \mathrm{N}$ & RFMS & 150 & 278 & 69 & 3.52 & {$[124]$} \\
$\mathrm{CuCrO}_{2}$ & CVD & 140 & 17 & 50 & 3.20 & {$[125]$} \\
$\mathrm{Cu}_{0.66} \mathrm{Cr}_{1.33} \mathrm{O}_{2}$ & CVD & 200 & 102 & 35 & 3.22 & {$[126]$} \\
$\mathrm{CuCrO}_{2}$ & Spray coating & 90 & 12 & 55 & - & {$[127]$} \\
$\mathrm{CuBO}_{2}$ & PLD & 200 & 1.65 & 85 & 4.50 & {$[47]$} \\
$\mathrm{CuGaO}_{2}$ & PLD & 500 & $6.3 \times 10^{-2}$ & 80 & 3.60 & {$[32]$} \\
$\mathrm{CuInO}_{2}: \mathrm{Ca}$ & PLD & 170 & $2.8 \times 10^{-3}$ & 70 & 3.90 & {$[35]$} \\
$\mathrm{SrCu}_{2} \mathrm{O}_{2}: \mathrm{K}$ & PLD & 120 & $4.8 \times 10^{-2}$ & 70 & 3.30 & {$[50]$} \\
$\mathrm{SrCu}_{2} \mathrm{O}_{2}$ & PLD & 220 & $4.5 \times 10^{-2}$ & 80 & 3.30 & {$[128]$} \\
\hline
\end{tabular}


(a)

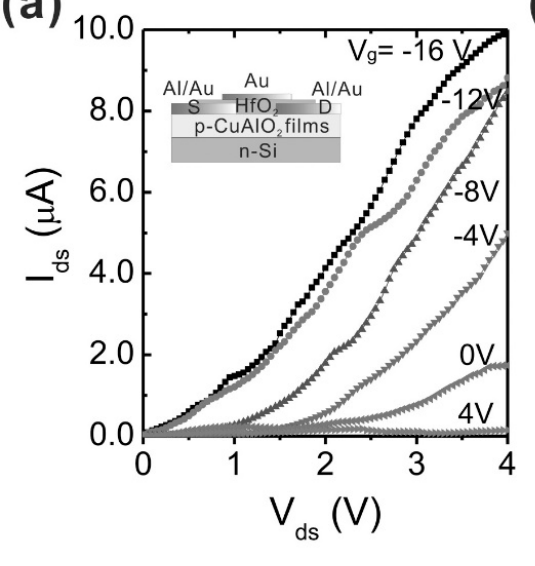

(b)

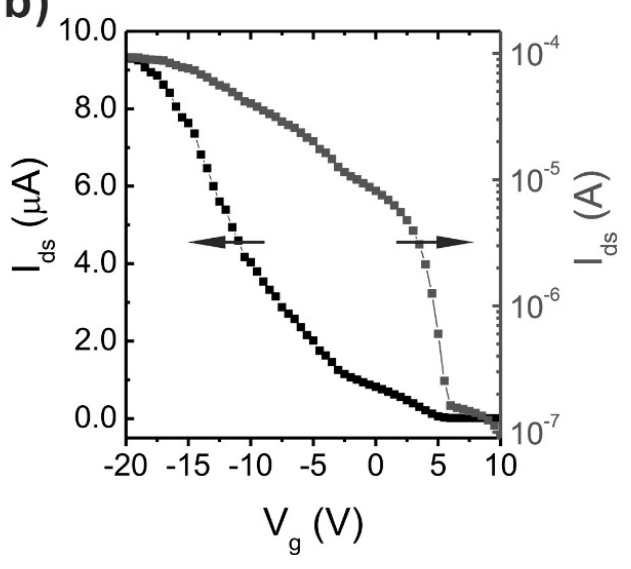

Figure 4. (a) The change of $I_{\mathrm{ds}}$ against $V_{\mathrm{ds}}$ at different $V_{\mathrm{g}}$ values; (b) The change of $I_{\mathrm{ds}}$ against $V_{\mathrm{g}}$ at $V_{\mathrm{ds}}$ at $3 \mathrm{~V}$. Inset in (a) is the schematic drawing of the thin-film transistor (TFT). Reproduced with permission from Ref. [120]. Copyright 2012 AIP Publishing.

Compared to the prototypical delafossite $\mathrm{CuAlO}_{2}, \mathrm{CuCrO}_{2}$ has been found to possess a higher p-type conductivity, especially after divalent atom doping such as $\mathrm{Mg}$. Moreover, it differs from other delafossites by having better hybridization between $\mathrm{M} 3 d$ states and $\mathrm{O} 2 p$ states, and possessing better dupability [129-131]. However, it has a poorer optical transparency due to the d-d transitions in $\mathrm{Cr}$ [58]. On the other hand, the intrinsic or stoichiometric $\mathrm{CuCrO}_{2}$ has rather low p-type conductivity of $10^{-4} \mathrm{~S} \cdot \mathrm{cm}^{-1}$, while the divalent atom doped or $\mathrm{Cu}$-deficient $\mathrm{CuCrO}_{2}$ possesses a high hole conductivity [126]. Until 2018, the $\mathrm{CuCrO}_{2}$ doped with $\mathrm{Mg}$ that was prepared by Nagarajan et al. in 2001 held the p-type conductivity record for delafossites of $220 \mathrm{~S} \cdot \mathrm{cm}^{-1}$, but it also had a poor optical transparency of 30\% [30]. An attempt to improve the transparency for such a film decreased the conductivity to around $1 \mathrm{~S} \cdot \mathrm{cm}^{-1}$. After the report of the high conductivity by that work, no following publications could be found for this system with a high conductivity. Many other dopants, including $\mathrm{Fe}, \mathrm{Ca}, \mathrm{Ni}, \mathrm{Sr}, \mathrm{Ba}$, and $\mathrm{Zn}$ have since been incorporated into the $\mathrm{CuCrO}_{2}$, but their p-type conductivity is much lower than $220 \mathrm{~S} \cdot \mathrm{cm}^{-1}$ [122,132-135]. Besides the substitution at the trivalent $\mathrm{M}$ sites, the $\mathrm{N}$ atom has been used as a substitute for the $\mathrm{O}$ atom in $\mathrm{CuCrO}_{2}$. It was found that the p-type conductivity increased by more than three orders to $17 \mathrm{~S} \cdot \mathrm{cm}^{-1}$ compared to the intrinsic state [123]. By combining both cation and anion substitution, a new record for p-type conductivity in delafossites has been reported to be $278 \mathrm{~S} \cdot \mathrm{cm}^{-1}$ in 2018 [124]. In this study, $\mathrm{Mg}$ and $\mathrm{N}$ dopants were introduced into the $\mathrm{CuCrO}_{2}$ thin film, which served to substitute $\mathrm{Cr}$ and $\mathrm{O}$, respectively. With the doping concentration of $2.5 \% \mathrm{Mg}$ and a $40 \% \mathrm{~N}_{2} /\left(\mathrm{N}_{2}+\mathrm{Ar}\right)$ ratio during sputtering, the $\mathrm{CuCrO}_{2}$ film had the record-high conductivity of $278 \mathrm{~S} \cdot \mathrm{cm}^{-1}$ and optical transparency of $69 \%$. A theoretical study using first-principle calculation on $\mathrm{Mg}$ and $\mathrm{N}$ co-doping has also supported the effectiveness of such an approach to improve p-type conductivity [136]. Possibly because this paper was published just recently, no other reports on such a high conductivity for this system can be found. Besides the $\mathrm{Mg}-\mathrm{N}$ doping, other co-doping strategies have also been studied, including Mg-Fe [133], Mg-S [137], and Ag-Mg [138], but the electrical and optical properties are not comparable to the study on $\mathrm{Mg}-\mathrm{N}$ doping [124].

Recently, $\mathrm{Cu}$-deficient $\mathrm{CuCrO}_{2}$ has been reported to possess a relatively high p-type conductivity, and their optical and electrical properties are tabulated in Table 1 [109,125-127,139]. In 2017, Popa et al. prepared highly $\mathrm{Cu}$-deficient $\mathrm{Cu}_{0.66} \mathrm{Cr}_{1.33} \mathrm{O}_{2}$ with a conductivity higher than $100 \mathrm{~S} \cdot \mathrm{cm}^{-1}$ without any intentional extrinsic doping, and this appears to be the highest conductivity value out of all the delafossites without extrinsic doping [126]. However, no other papers for a similarly high conductivity for this system have been reported since then. The origin of this high conductivity was proposed to be the high $\mathrm{Cu}$ deficiency, and the missing of part of a $\mathrm{Cu}$ plane was observed for the as-deposited $\mathrm{Cu}_{0.66} \mathrm{Cr}_{1.33} \mathrm{O}_{2}$ film. After high-temperature annealing at $900{ }^{\circ} \mathrm{C}$, the $\mathrm{CuCrO}_{2}$ film restored its stoichiometric ratio with $\mathrm{Cr}_{2} \mathrm{O}_{3}$ precipitates. The electrical conductivity dropped significantly as 
the $\mathrm{Cu}$ defect was healed, which suggests that the $\mathrm{Cu}$ deficiency defect is metastable [126]. Besides the quest for only high-performance $\mathrm{CuCrO}_{2}$, more cost-efficient polymer substrates that are compatible with low-temperature chemical solution methods have been developed recently, and all of the $\mathrm{CuCrO}_{2}$ films that were fabricated depicted a $\mathrm{Cu}$ deficiency with a high p-type conductivity $[109,127,139]$. It is known that high-temperature processing for these p-type oxides makes them unsuitable for flexible applications using polymer substrates [140]. In 2018, Wang et al. investigated a low-process temperature at $180^{\circ} \mathrm{C}$ to prepare $\mathrm{CuCrO}_{2}$ delafossites, and p-n diode and organic photovoltaic devices have been prepared successfully [139]. Also, several solution-based $\mathrm{CuCrO}_{2}$ thin films have been fabricated and investigated for their applications, including p-n junctions, thermoelectric devices, and organic solar cells [141-143]. Recently, Nie developed a solution-based $\mathrm{CuCrO}_{2}$ thin-film transistor (TFT) device [109]. A high on/off ratio of around $10^{5}$ and good field effect mobility of $0.59 \mathrm{~cm}^{2} \cdot \mathrm{V}^{-1} \cdot \mathrm{s}^{-1}$ was achieved.

The good performance of $\mathrm{CuCrO}_{2}$ encouraged research groups to study the effect of trivalent $\mathrm{M}$ in $\mathrm{CuMO}_{2}$ delafossites in detail. It has been explained before that the presence of $\mathrm{Cu}-\mathrm{O}-\mathrm{Cu}$ linkage in $\mathrm{Cu}_{2} \mathrm{O}$ gives a high hole mobility in $\mathrm{Cu}_{2} \mathrm{O}$ because of the hybridization of $\mathrm{Cu}$ and $\mathrm{O}$ states, but the trivalent $\mathrm{M}$ is involved in the $\mathrm{Cu}-\mathrm{O}-\mathrm{M}-\mathrm{O}-\mathrm{Cu}$ linkage in delafossites. This would lead to a lower mobility in delafossites. On the other hand, the higher conductivity of $\mathrm{CuCrO}_{2}$ might be caused by the hybridization of $\mathrm{Cr} 3 d$ states in the linkage [42]. It has also been theoretically shown that Cr $3 d$ states would hybridize with O $2 p$ states to form more dispersed VBM, leading to lower hole effective mass [131]. However, different conducting mechanisms of $\mathrm{Mg}$-doped $\mathrm{CuCrO}_{2}$ have been proposed over the years, including the p-type conduction through $\mathrm{Cu}^{2+} / \mathrm{Cu}^{+}[134] \mathrm{or} \mathrm{Cr}^{4+} / \mathrm{Cr}^{3+}$ [144]. Unfortunately, the exact role of trivalent $\mathrm{M}$ on the conductivity is still not fully understood yet. This complexity is partially caused by the difficulty to locate the exact $\mathrm{Cr} 3 d$ state energy position [134,145]. In 2013, Yokobori et al. performed resonant photoelectron spectroscopy (PES) on $\mathrm{CuCrO}_{2}: \mathrm{Mg}$, and the $\mathrm{Cu}-\mathrm{Cr} 3 d-3 p$ resonant PES spectra showed that VBM was primarily composed of $\mathrm{Cr} 3 d$ states [146]. This work suggested that the holes generated in the oxides would also be delocalized to $\mathrm{Cr}$ sites, leading to a larger hole mobility. However, this report also showed that holes would be localized onto $\mathrm{Cu}$ sites according to X-ray absorption spectroscopy (XAS). Nevertheless, it is generally believed that the VBM is mainly formed by $\mathrm{Cu} 3 d$ states, and this is consistent with the X-ray photoelectron spectroscopy (XPS) studies [129]. Another theoretical study by Scanlon et al. suggested that the high p-type conductivity of $\mathrm{CuCrO}_{2}$ originates from the well hybridization of $\mathrm{Cr} 3 d$ states with $\mathrm{O} 2 p$ states, which would improve hole conductivity [56]. Indeed, more experimental and theoretical studies should be carried out to investigate the mechanism of conductivity enhancement for $\mathrm{CuCrO}_{2}$ and compare it to other delafossites. Another controversial issue for $\mathrm{CuCrO}_{2}$ is whether it is a direct or indirect band-gap oxide $[29,147,148]$. It has been often reported to have an indirect band gap around 2.5-2.8 eV and a direct band gap around 3.0-3.3 eV [29], although it was also shown to possess only a fundamental band gap of $3.2 \mathrm{eV}$ [147]. A later detailed simulation study has proven that $\mathrm{CuCrO}_{2}$ indeed possesses an indirect band gap [56].

By building on the studies of trivalent $\mathrm{M}$ effects, $\mathrm{CuBO}_{2}$ was later proposed as a potential p-type TCO [47]. This is because the $\mathrm{B}$ in $\mathrm{CuBO}_{2}$ has the smallest ionic size in the delafossite family, which will significantly increase the optical band gap according to the theoretical studies [77,149]. Snure et al. prepared $\mathrm{CuBO}_{2}$ film by using PLD for the first time, and a decent p-type conductivity of $1.65 \mathrm{~S} \cdot \mathrm{cm}^{-1}$ with a high optical transparency higher than $85 \%$ at the 550 -nm wavelength was achieved [47]. However, it was noted that an indirect band gap at $2.2 \mathrm{eV}$ was observed, and transmittance dropped greatly below the 550-nm wavelength. Later studies have been carried out to prepare nanocrystalline or microstructure $\mathrm{CuBO}_{2}$ via chemical solution methods, although the performance in terms of the electrical conductivity and optical transmittance is not comparable to the $\mathrm{CuCrO}_{2}$ films, as discussed before [150-152]. Another popular delafossite under intense research investigation is $\mathrm{CuGaO}_{2}$, which was firstly prepared by Yanagi et al. in 2000 [33]. Early studies showed that $\mathrm{CuGaO}_{2}$ has rather good optical transparency (higher than $80 \%$ ) with decent electrical conductivity [32]. Due to its good 
optical properties and ease of nanostructure synthesis, $\mathrm{CuGaO}_{2}$ has been studied for the applications of p-type dye-sensitized or perovskite solar cells [54,153-156]. For example, $\mathrm{CuGaO}_{2}$ has been used as a HTL in the perovskite solar cell $\mathrm{CH}_{3} \mathrm{NH}_{3} \mathrm{PbI}_{3-x} \mathrm{Cl}_{x}$ with a high power conversion efficiency (PCE) of $18.51 \%$ due to the good transparency, relatively high mobility, and proper low-lying VBM [54]. The structure of both the material $\mathrm{CuGaO}_{2}$ and the whole solar cell device with its band diagram is shown in Figure 5. As can be seen from the schematic energy band diagram, holes in the organic semiconducting perovskite layers can be transported to the $\mathrm{CuGaO}_{2}$ layer effectively due to their well-matched energy levels. Another promising delafossite is $\mathrm{CuInO}_{2}$, as it had been found to be a bipolar semiconductor. By either $\mathrm{Ca}$ or Sn doping, $\mathrm{CuInO}_{2}$ could be made into a p-type or n-type TCO, respectively, and all of the oxide transparent p-n homojunctions could be fabricated [35-37,149]. The rather unique bipolar property could be explained by the theory of equilibrium doping and the doping limit rule [149,157-160]. The VBM and CBM positions directly influence the extent of self-compensation. A higher VBM could allow for easier p-type doping, while a lower CBM could also induce easier n-type doping. In the case of $\mathrm{CuInO}_{2}$, it has a high VBM similar to other delafossites, contributing to its p-type dopability. However, the CBM lies at a much lower energy level compared to other delafossites $\left(1.48 \mathrm{eV}\right.$ lower than $\left.\mathrm{CuAlO}_{2}\right)$ due to the low-lying In states, leading to its n-type dupability [149]. It is also interesting to note that delafossites with larger ionic sizes of trivalent metal $\mathrm{M}$ such as $\mathrm{CuLaO}_{2}, \mathrm{CuYO}_{2}$, and $\mathrm{CuScO}_{2}$ could accommodate additional oxygen atoms [161]. Unlike other delafossites with smaller $\mathrm{M}$ sizes such as $\mathrm{CuCrO}_{2}$, oxygen interstitials start to contribute to the p-type conductivity in those delafossites with larger M ionic sizes [38,162]. Treating thin films such as $\mathrm{CuScO}_{2}$ at a high temperature $\left(400-500{ }^{\circ} \mathrm{C}\right)$ in oxygen-rich atmosphere could incorporate a large amount of oxygen $\left(\mathrm{CuScO}_{2.5}\right)$ and enhance the conductivity [38].

a

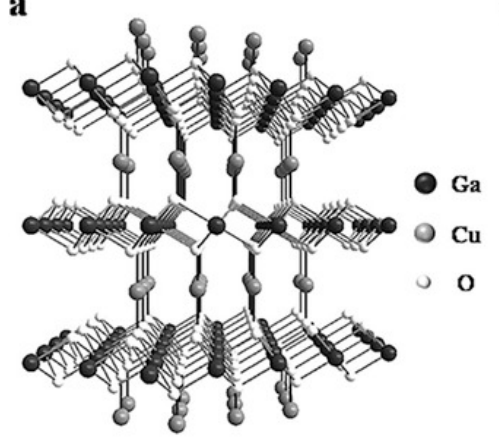

b

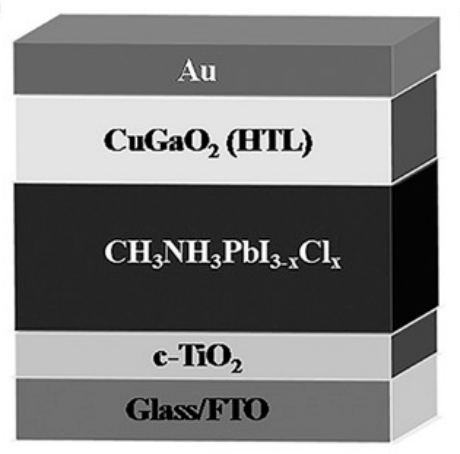

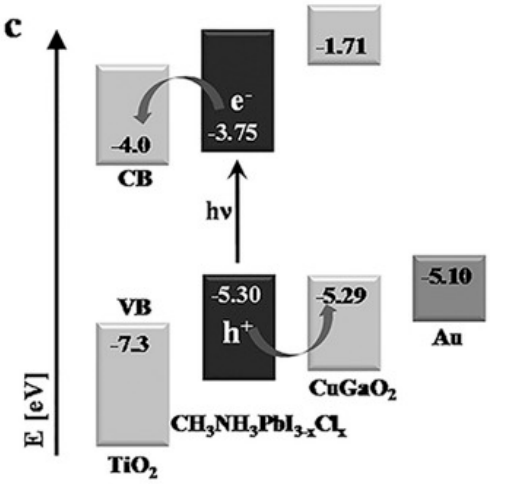

Figure 5. (a) Crystal structure of $\mathrm{CuGaO}_{2},(\mathbf{b})$ schematic illustration of the solar cell device, and (c) band diagram of the materials in the device. Reproduced with permission from Ref. [54]. Copyright 2017 Wiley.

Apart from the $\mathrm{CuMO}_{2}$ delafossites discussed so far, $\mathrm{SrCu}_{2} \mathrm{O}_{2}$ is another important $\mathrm{Cu}$-based one that is used as a p-type transparent semiconductor. It was proposed on the same basis as the selection rules of delafossites, and it has similar working principles for the VBM formation with delafossites or $\mathrm{Cu}_{2} \mathrm{O}$ [50]. It has a tetragonal crystal structure with $\mathrm{O}-\mathrm{Cu}-\mathrm{O}$ dumbbell bonding (as shown in Figure 6a), which is similar to delafossites or $\mathrm{Cu}_{2} \mathrm{O}$. These dumbbell bonds form the one-dimension chain in a zigzag manner, so the transparency could be improved [50]. From both the first-principle calculations and experiments, $\mathrm{SrCu}_{2} \mathrm{O}_{2}$ was found to possess a direct band gap of $3.3 \mathrm{eV}$, and the VBM is formed by $\mathrm{Cu} 3 d-4 s p$ orbitals and $\mathrm{O} 2 p$ orbitals, leading to higher hole mobility [163]. Dopant $\mathrm{K}$ was found to be useful for the partial substitution at the $\mathrm{Sr}$ site to generate holes, and the conductivity improved from $3.9 \times 10^{-3}$ to $4.8 \times 10^{-2} \mathrm{~S} \cdot \mathrm{cm}^{-1}$, while the transparency at a visible range remained largely unchanged [50]. Due to its relatively low processing or deposition temperature, which are as low as $300{ }^{\circ} \mathrm{C}$, an all-oxide transparent p-n junction (shown in Figure $6 \mathrm{~b}$ ) was made by $\mathrm{ZnO} / \mathrm{SrCu}_{2} \mathrm{O}_{2}$ with a device transparency higher than $70 \%$ and an ideality factor of 1.62 [164], 
and several UV/near-UV emitting diodes were constructed [52,165,166]. Even though the direct band gap $\mathrm{SrCu}_{2} \mathrm{O}_{2}$ has a relatively strong photoluminescence (PL) peak at around $500 \mathrm{~nm}$, the light emitted by heteroepitaxial grown $\mathrm{ZnO} / \mathrm{SrCu}_{2} \mathrm{O}_{2}$ was shown to be originated from the $\mathrm{ZnO}$ layer with an emission peak around $380 \mathrm{~nm}$ [166].

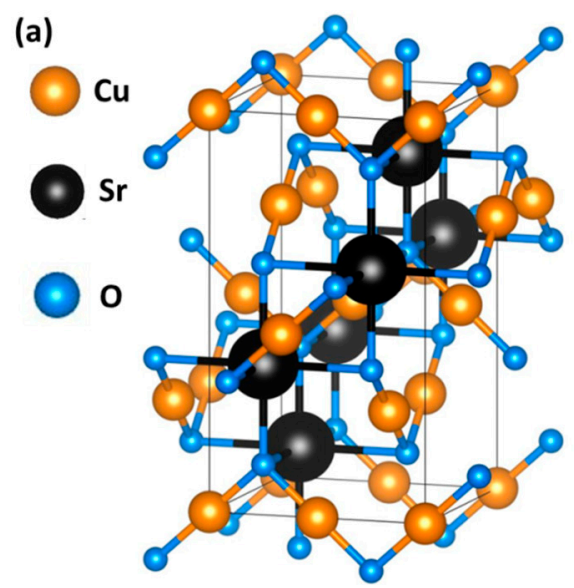

(b)

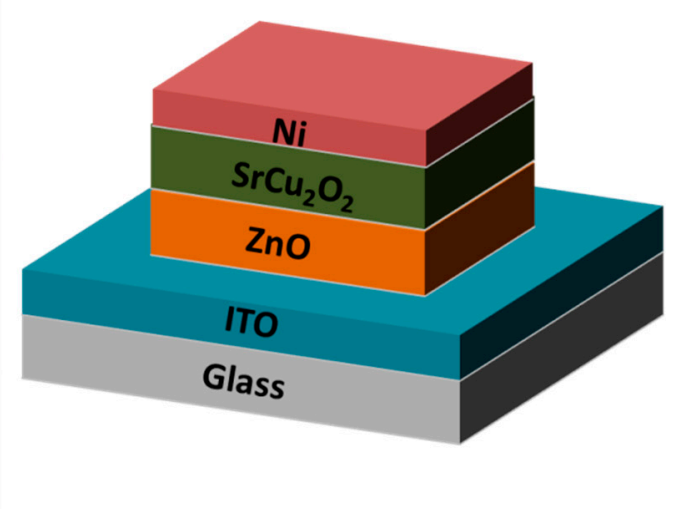

Figure 6. (a) Crystal structure of $\mathrm{SrCu}_{2} \mathrm{O}_{2}$; (b) Schematic drawing of a typical p-n junction by $\mathrm{ZnO} / \mathrm{SrCu}_{2} \mathrm{O}_{2}$.

\subsection{Oxychalcogenides}

As briefly discussed before, the delafossite has the limitation of relatively low mobility, and its conduction mechanism is based on polaronic hopping. It had been proposed that oxychalcogenide, with its prototypical form, LaCuOS, would achieve better electrical performance with higher mobility [87]. As the VBM is mainly formed by the well hybridization between $\mathrm{Cu} 3 d$ orbitals and S $3 p$ orbital states, this could achieve higher mobility compared to delafossites as more spatially dispersed VBM is formed [167]. Since the introduction of the first oxychalcogenide (LaCuOS) as a p-type transparent material in 2000 by Ueda et al., many forms of oxychalcogenides with the formula $\mathrm{LnCuOCh}(\mathrm{Ln}=\mathrm{La}, \mathrm{Y}, \mathrm{Pr}$, etc., and $\mathrm{Ch}=\mathrm{S}$, Se, Te, etc.) have been investigated [168]. It was later reported that doping LaCuOS with $\mathrm{Sr}$ could increase its conductivity to $0.26 \mathrm{~S} \cdot \mathrm{cm}^{-1}$ [169]. The band gap would decrease when La was replaced with other Ln elements $(\mathrm{Ln}=\operatorname{Pr}$ and Nd) [170]. Similarly, the band gap would decrease when sulfide (S) was replaced by other chalcogens such as Se and Te, and the p-type conductivity would increase at the same time [171]. Among the various dopants that have been used to date, $\mathrm{Mg}$ dopants delivered rather good results. It has been reported that $\mathrm{LaCuOSe}$ doped with $\mathrm{Mg}$ exhibited a p-type conductivity of $910 \mathrm{~S} \cdot \mathrm{cm}^{-1}$ without an indication of transparency [63]. Another interesting oxychalcogenide is $\left[\mathrm{Cu}_{2} \mathrm{~S}_{2}\right]\left[\mathrm{Sr}_{3} \mathrm{Sc}_{2} \mathrm{O}_{5}\right]$, where $\left[\mathrm{Sr}_{3} \mathrm{Sc}_{2} \mathrm{O}_{5}\right]$ replaced the $\left[\mathrm{La}_{2} \mathrm{O}_{2}\right]$ group. This undoped oxychalcogenide with a wide band gap of $3.14 \mathrm{eV}$ has a p-type conductivity of $2.8 \mathrm{~S} \cdot \mathrm{cm}^{-1}$, which is even higher than the undoped $\mathrm{CuBO}_{2}$ [47] that has a high intrinsic p-type conductivity in the delafossite family [172]. The source of this high undoped conductivity is its extremely high hole mobility of $150 \mathrm{~cm}^{2} \cdot \mathrm{V}^{-1} \cdot \mathrm{s}^{-1}$, which is higher than any other p-type TCOs, and even higher than the highest mobility of n-type TCOs [173]. Strangely, no follow-up experimental works have been reported on this material since that work.

LnCuOCh belongs to the tetragonal system with the space group $\mathrm{P} 4 / \mathrm{nmm}$, and it has a layered structure with alternating $\left[\mathrm{Ln}_{2} \mathrm{O}_{2}\right]^{2+}$ and $\left[\mathrm{Cu}_{2} \mathrm{~S}_{2}\right]^{2-}$ layers along the c-axis, as shown in Figure 7a. In each layer, the structure of $\left[\mathrm{Ln}_{2} \mathrm{O}_{2}\right]^{2+}$ has a PbO type, while that of the $\left[\mathrm{Cu}_{2} \mathrm{~S}_{2}\right]^{2-}$ layer has an anti-PbO type $[172,174]$. It has also been reported that the $\left[\mathrm{Ln}_{2} \mathrm{O}_{2}\right]^{2+}$ layer is much more resistive to hole carriers than the $\left[\mathrm{Cu}_{2} \mathrm{~S}_{2}\right]^{2-}$ layer, and the $\left[\mathrm{Cu}_{2} \mathrm{~S}_{2}\right]^{2-}$ layer is indeed the hole transporting path [62]. Moreover, the two-dimensional characteristics demonstrated by the layered LnCuOCh could suggest its similarity to the artificial multiple quantum wells (MQWs). From the energy-band calculations, 
it should be regarded as a natural MQW due to its hole confinement effect between the insulating $\left[\mathrm{Ln}_{2} \mathrm{O}_{2}\right]^{2+}$ layers, which leads to many novel electronics applications [62]. This two-dimensional quantum confinement effect leading to the relatively large exciton binding energy of around $50 \mathrm{meV}$ for $\mathrm{LnCuOCh}$, resulting in good photoluminescence (PL) performance at room temperature, which also indicates its direct band-gap characteristic $[170,175]$.

(a)

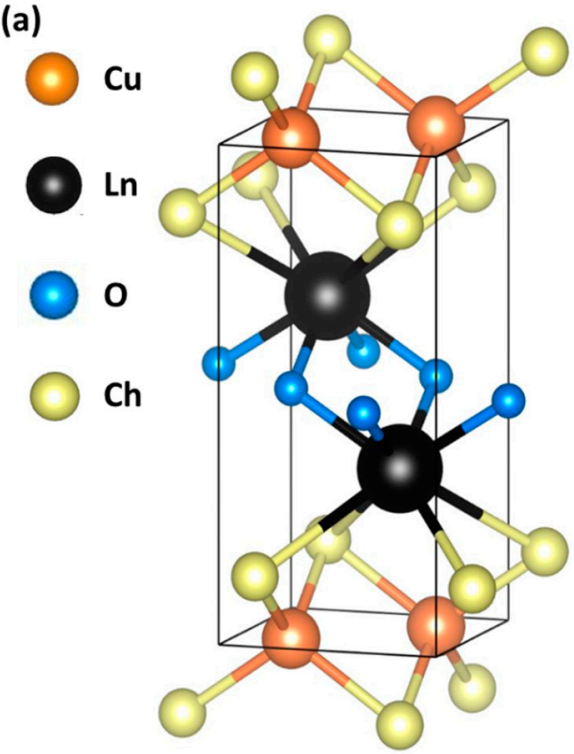

(b)

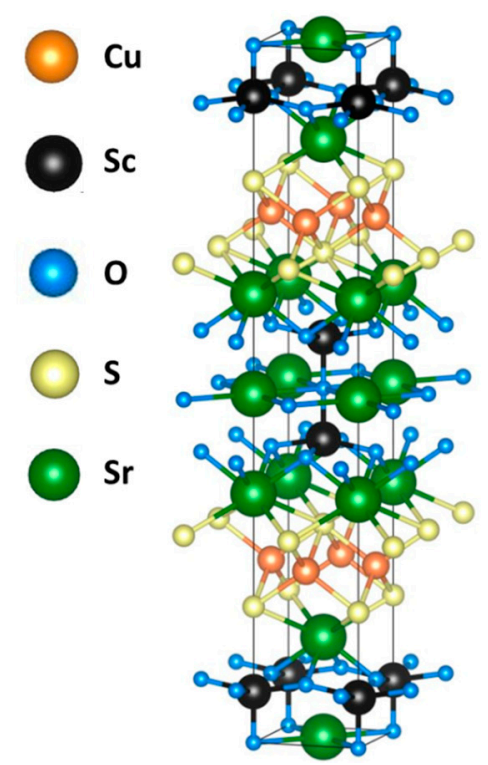

Figure 7. Crystal structure of (a) $\mathrm{LnCuOCh}(\mathrm{Ln}=\mathrm{La}, \mathrm{Y}, \mathrm{Pr}$, etc., and $\mathrm{Ch}=\mathrm{S}, \mathrm{Se}, \mathrm{Te}$, etc.) and (b) $\left[\mathrm{Cu}_{2} \mathrm{~S}_{2}\right]\left[\mathrm{Sr}_{3} \mathrm{Sc}_{2} \mathrm{O}_{5}\right]$.

One of the advantages of oxychalcogenides compared to other oxides is the tunability of their physical properties [14]. By changing the chalcogen elements from $S$ through Se to Te, the conductivity, band gap, and other physical properties can be tuned. Usually, oxides are more robust compared to chalcogenides, resulting in a limited ability to be tuned. Moreover, as the quaternary layered structure, oxychalcogenides have more degrees of freedom for exploring more possibilities. In the series of $\mathrm{LaCuOCh}$, the band gaps decrease from $\mathrm{LaCuOS}$ of $3.14 \mathrm{eV}$ via LaCuOSe of $2.8 \mathrm{eV}$ to LaCuOTe of $2.4 \mathrm{eV}$ [176]. This is caused by the energy-level differences among the Ch p orbitals, as the VBM is formed by the hybridization between the $\mathrm{Cu} 3 d$ and $\mathrm{Ch} p$ orbitals (as shown in Figure 8) [177]. Therefore, LaCuOTe has the highest degree of hybridization for its VBM, leading to the highest hole mobility among all $\mathrm{LaCuOCh}$. However, it should be noted that LaCuOTe has an indirect band gap and no room temperature PL signal, and both $\mathrm{LaCuOS}$ and $\mathrm{LaCuOSe}$ have direct band gaps with intense PL signals [171]. On the other hand, for LnCuOS series, the band gaps decrease from LaCuOS of $3.14 \mathrm{eV}$ via PrCuOS of $3.03 \mathrm{eV}$ to NdCuOS of $2.98 \mathrm{eV}$ [174]. Unlike the case for Ch substitution, as discussed before, the band gap does not correlate with the energy levels of $\mathrm{Ln}$ orbitals in the $\left[\mathrm{Ln}_{2} \mathrm{O}_{2}\right]^{2+}$ layer directly [170]. Instead, the substitution of Ln from La via Pr to $\mathrm{Nd}$ decreases the a-axis parameter, and this would reduce the $\mathrm{Cu}-\mathrm{Cu}$ distance. The reduction in the distance would lead to higher $\mathrm{Cu} 4 \mathrm{~s}$ interaction, resulting in the $\mathrm{Cu} 4 \mathrm{~s}$ related band broadening, and thus a lower band gap that is similar to the case of YCuOSe (shown in Figure 8) [178]. 


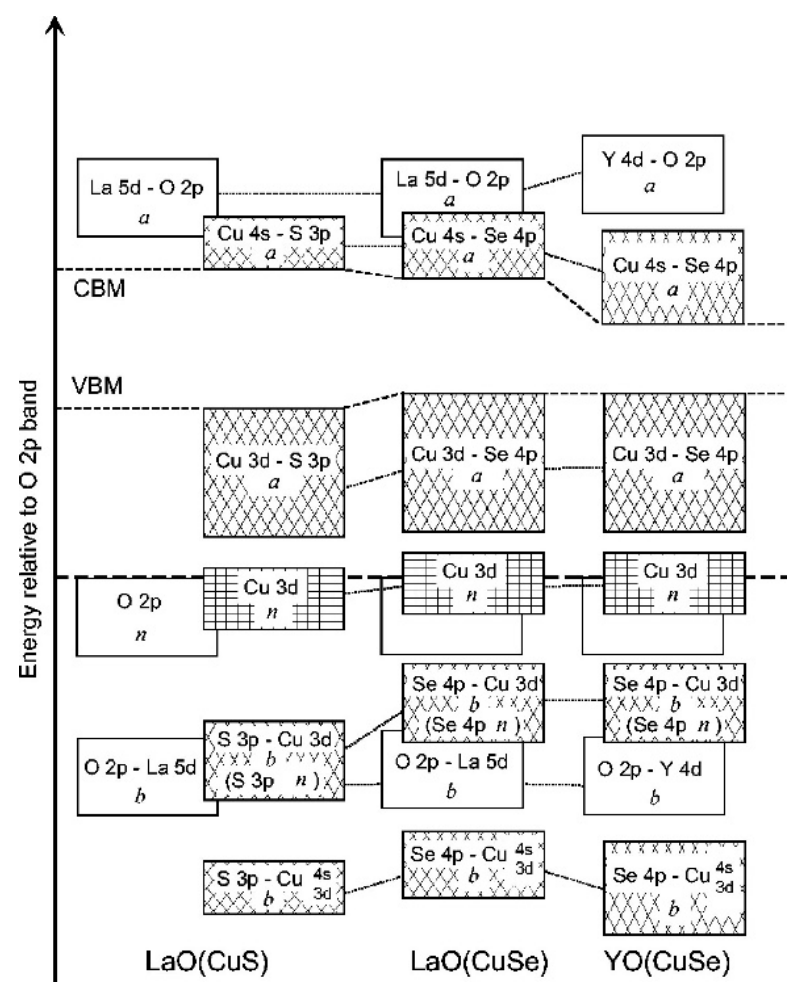

Figure 8. Schematic diagram of the band structures of LaCuOS, LaCuOSe, and YOCuSe from the first-principle calculation. Reproduced with permission from Ref. [178]. Copyright 2007 AIP Publishing.

In 2000, Ueda et al. firstly introduced LaCuOS as a potential p-type oxychalcogenide in the form of polycrystalline thin film [168]. The intrinsic LaCuOS after post-annealing is a partially transparent semiconducting film with a conductivity of $1.2 \times 10^{-2} \mathrm{~S} \cdot \mathrm{cm}^{-1}$ and transmittance higher than $70 \%$. After $5 \%$ Sr doping, the conductivity was improved more than one order to $2.6 \times 10^{-1} \mathrm{~S} \cdot \mathrm{cm}^{-1}$. After optimizing the Sr doping concentration to $3 \%$, the conductivity was further increased to $20 \mathrm{~S} \cdot \mathrm{cm}^{-1}$ [179]. Similarly, the incorporation of a bivalent $\mathrm{Sr}$ atom was also found to be effective for polycrystalline $\mathrm{LaCuOSe}$ and other LnCuOCh materials for conductivity enhancement $[174,180]$. However, Sr doping was shown to be ineffective for epitaxial $\mathrm{LaCuOCh}$ film, and $\mathrm{Mg}$ was found to be able to improve the conductivity in this case [181]. As mentioned before, the Mg-doped expitaxial film LaCuOSe by reactive solid-phase epitaxy (R-SPE) is still holding the p-type conductivity record of $910 \mathrm{~S} \cdot \mathrm{cm}^{-1}$ among all the p-type TCOs [63]. The less than $1 \% \mathrm{Mg}$ doping in the 40-nm thin film attained degenerate conduction, which cannot be achieved by Ca or Sr doping $[168,179]$. Due to the high hole concentration of higher than $10^{21} \mathrm{~cm}^{-3}$, free carrier absorption (FCA) was present in such film, and optical absorption in the visible light and infrared region occurs [182]. From the Drude model, the effective mass of the holes could be calculated from FCA [183]. Moreover, such a high hole concentration is only present in such thin films with thicknesses of $40 \mathrm{~nm}$, and is absent in thicker films of $150 \mathrm{~nm}$, and hole concentration is much higher than the $\mathrm{Mg}$ doping concentration $[63,175]$. As the $\mathrm{Cu}$ concentration varies according to depth in thinner films (40-nm thickness), this suggested that the origin of hole generation is related to $\mathrm{Cu}$ vacancies [63]. Another interesting and surprising feature of this high conductivity film is that the mobility after doping only dropped a little, and this is because the hole carriers are transferred to the $\left[\mathrm{Cu}_{2} \mathrm{Se}_{2}\right]$ layer, so the holes are not scattered by the charged impurities [184]. However, it suffers from poor transparency due to the lower band gap of $2.8 \mathrm{eV}$ and subgap optical absorption ranging from 2.0 to $2.8 \mathrm{eV}$ [13]. On the other hand, Mg-doped LaCuOSe, which is a p-type degenerate semiconductor, does not experience a Moss-Burstein (MB) shift, which is a blue shift of the optical absorption [185]. Instead, subgap absorption is observed, and its origin is not yet well understood [13]. This has been suggested by the observation that the acceptor defects 
in LaCuOSe keep the Fermi level above the VBM, leading to the absence of an MB shift effect [173]. Moreover, from the theoretical calculation and perspective of cation radius, Sr should be the optimal dopant, followed by $\mathrm{Ca}$ for $\mathrm{LaCuOCh}$, instead of $\mathrm{Mg}$ [173]. While the explanation for this phenomenon is not clear yet, it could be related to the origin of the conduction mechanism in LnCuOCh. It has been shown that the source of p-type conductivity in $\mathrm{LnCuOCh}$ is $\mathrm{Cu}$ deficiency, where $\mathrm{Cu}$ vacancies are the acceptor defects [186]. The presence of $\mathrm{Mg}$ does not directly contribute a hole by substituting Ln sites; instead, it serves to enhance the $\mathrm{Cu}$ vacancies, leading to higher hole concentrations [13]. The electrical and optical properties of selected oxychalcogenides are tabulated in Table 2. Besides the improvement of the properties for $\mathrm{LnCuOCh}$ materials, several devices were also fabricated to demonstrate their good optoelectronic performances $[187,188]$. Hiramatsu et al. prepared a LED in the blue-ultraviolet region by using LaCuOSe as the p-type material and $\mathrm{InGaZn}_{5} \mathrm{O}_{8}$ as the n-type material [187]. This p-n heterojunction has demonstrated a strong and sharp electroluminescence at the 430-nm wavelength at room temperature. Later, Yanagi et al. used LaCuOSe doped with $\mathrm{Mg}$ as the hole injection layer/electrode for OLEDs [188]. The LaCuOSe:Mg that was used in that work offered advantages over the widely used ITO, including a lower hole injection barrier, higher current drivability, and lower threshold voltage.

Table 2. Summary of selected oxychalcogenides with their material properties including thickness $(d)$, conductivity $(\sigma)$, transmittance $(T)$, and optical band gap $\left(E_{\mathrm{g}}\right)$.

\begin{tabular}{ccccccc}
\hline Oxychalcogenides & Fabrication & $\boldsymbol{d}(\mathbf{n m})$ & $\boldsymbol{\sigma} \mathbf{( S \cdot \mathbf { c m } ^ { - \mathbf { 1 } } )}$ & $\boldsymbol{T} \mathbf{( \% )}$ & $\boldsymbol{E}_{\mathbf{g}}(\mathbf{e V})$ & Ref. \\
\hline LaCuOS & RFMS & 200 & $1.2 \times 10^{-2}$ & 70 & 3.1 & {$[168]$} \\
LaCuOS:Sr & RFMS & 150 & 20 & 60 & 3.1 & {$[179]$} \\
PrCuOS:Sr & RFMS & 150 & 1.8 & - & 3.03 & {$[174]$} \\
NdCuOS:Sr & RFMS & 150 & 0.32 & - & 2.98 & {$[174]$} \\
LaCuOSe:Mg & PLD & 40 & 910 & 30 & 2.8 & {$[63]$} \\
LaCuOSe & PLD & 150 & 24 & - & 2.8 & {$[175]$} \\
YCuOSe (Bulk) & - & - & 0.14 & - & 2.58 & {$[178]$} \\
{$\left[\mathrm{Cu}_{2} \mathrm{~S}_{2}\right]\left[\mathrm{Sr}_{3} \mathrm{Sc}_{2} \mathrm{O}_{5}\right]($ Bulk $)$} & - & - & 2.8 & - & 3.1 & {$[172]$} \\
NdCuOS:Mg & Dip coating & 200 & 52.1 & 54.3 & 2.91 & {$[189]$} \\
\hline
\end{tabular}

YCuOSe was synthesized by Ueda et al. in 2007, and its optical and electrical properties were studied, and this lead to a deeper understanding of the effects of Ln or Ch substitution [178]. However, YCuOSe has a rather small band gap of $2.58 \mathrm{eV}$, originating from the short $\mathrm{Cu}-\mathrm{Cu}$ distances. While it has a much higher intrinsic conductivity than LaCuOSe, its small band gap limits its applications for transparent electronics. However, a similar compound, $\mathrm{YCuOS}$, which is expected to depict a larger band gap, has not been successfully prepared yet, so more works should be devoted to achieve such a phase. Other than $\mathrm{YCuOSe}$, another very promising oxychalcogenide $\left[\mathrm{Cu}_{2} \mathrm{~S}_{2}\right]\left[\mathrm{Sr}_{3} \mathrm{Sc}_{2} \mathrm{O}_{5}\right]$ was proposed and synthesized by Liu et al. in polycrystalline bulk form via solid-state reaction in the same year [172]. It has a similar crystal structure as $\mathrm{LnCuOCh}$, with the $\left[\mathrm{Ln}_{2} \mathrm{O}_{2}\right]^{2+}$ layer being replaced with the $\left[\mathrm{Sr}_{3} \mathrm{Sc}_{2} \mathrm{O}_{5}\right]^{2+}$ layer (shown in Figure $7 \mathrm{~b}$ ). The rather ionic perovskite $\left[\mathrm{Sr}_{3} \mathrm{Sc}_{2} \mathrm{O}_{5}\right]$ layer serves to preserve the large direct band gap of $3.1 \mathrm{eV}$. As discussed above for the case of Ln substitution, ionic trivalent ions of a larger size such as La and bivalent ions such as Ba could replace Sr and Sc, respectively, to increase the optical band gap [10]. With the band gap enhancement, the possibility of S substitution by Se to further improve the p-type mobility could be realized without affecting the transparency in visible light range. More importantly, there are two cation sites for doping, $\mathrm{Sr}^{2+}$ and $\mathrm{Sc}^{3+}$, to enhance the conductivity compared to the single cation site in other oxychalcogenides. The high hole mobility in this layered oxychalcogenide originated from the large dispersion of VBM [10]. Unfortunately, no subsequent experimental work has been reported by any research group for this promising $\left[\mathrm{Cu}_{2} \mathrm{~S}_{2}\right]\left[\mathrm{Sr}_{3} \mathrm{Sc}_{2} \mathrm{O}_{5}\right]$ layered material. This might partly be due to the difficulty of achieving such a phase via conventional methods, but it is worthwhile to re-investigate such a material and unfold its full potential. 
So far, the most popular synthesis method to prepare $\mathrm{LnCuOCh}$ is solid-state reaction, which involves the mixing of precursor oxides and sulfides such as $\mathrm{Ln}_{2} \mathrm{O}_{3}, \mathrm{Ln}, \mathrm{Cu}_{2} \mathrm{O}, \mathrm{Cu}_{2} \mathrm{~S}$, and $\mathrm{La}_{2} \mathrm{~S}_{3}$, etc., and sintering at high temperature for a long time. While this is the most straightforward preparation method, some of the starting materials such as $\mathrm{Ln}_{2} \mathrm{O}_{3}$ and $\mathrm{Ln}$ are either very sensitive to air or expensive [190]. This led to the development of an alternative synthesis method. In 2008, Nakachi and Ueda developed a flux method to prepare single-crystal LaCuOS in a relatively large size of $3.0 \times 2.8 \times 0.049 \mathrm{~mm}^{3}$ with a low conductivity of $7.1 \times 10^{-4} \mathrm{~S} \cdot \mathrm{cm}^{-1}$ and transmittance around $60 \%$ [191]. However, this method has the drawbacks of complexity in the experimental set-up, and long synthesis duration. Alternatively, chemical solution-based solvothermal and precipitation/reduction methods were proposed in 2010 and 2016, respectively, to prepare bulk LaCuOS [192,193]. Single-phase $\mathrm{LaCuOS}$ could be produced, and the solvothermal method could synthesize LaCuOS at a relatively low temperature of $200{ }^{\circ} \mathrm{C}$, making it compatible with a flexible substrate such as polyethylene terephthalate (PET). Unfortunately, the important electrical properties of such a material were not characterized in those two reports. Then, in 2017, Zhang et al. proposed a novel two-step synthesis method by combining a solid-state reaction with a sulfurization method [194]. Relatively stable and low-cost starting materials including $\mathrm{Cu}_{2} \mathrm{O}$ and $\mathrm{La}_{2} \mathrm{O}_{3}$ were used for the first step of the solid-state reaction to prepare $\mathrm{CuLaO}_{2}$, and then, the oxide $\mathrm{CuLaO}_{2}$ was sulfurized with $\mathrm{S}$ instead of the usually used compound $\mathrm{H}_{2} \mathrm{~S}$, which is highly toxic. Single-phase LaCuOS with a relatively high resistivity of $0.25 \mathrm{M} \Omega$ was produced. Besides the bulk LnCuOCh synthesis, its thin film form was normally prepared by a vacuum-based deposition method including RFMS, and PLD of the LnCuOCh target prepared via a solid solution method $[168,175,181,195]$. Such a conventional thin-film fabrication method has the drawback of time-consuming target preparation and the necessity of the use of $\mathrm{H}_{2} \mathrm{~S}$ during film deposition for both PLD and sputtering. Later, in 2018, Zhang et al. successfully prepared a LaCuOS film via a hydrogen-free method without using $\mathrm{H}_{2} \mathrm{~S}$, and the schematic illustration of the fabrication process is shown in Figure 9 [196]. More importantly, the hydrogen-containing gas $\mathrm{H}_{2} \mathrm{~S}$ was normally used in the thin film deposition process prior to that work. This might impede the p-type performance of oxychalcogenides such as $\mathrm{H}$, which is known to be an n-type dopant, and might be accidentally incorporated in the deposited thin film. Therefore, the absence of $\mathrm{H}_{2} \mathrm{~S}$ in that work not only serves to be more environmental friendly, but also improves the p-type conductivity, and the intrinsic conductivity in that work is as high as $0.3 \mathrm{~S} \cdot \mathrm{cm}^{-1}$ [196].

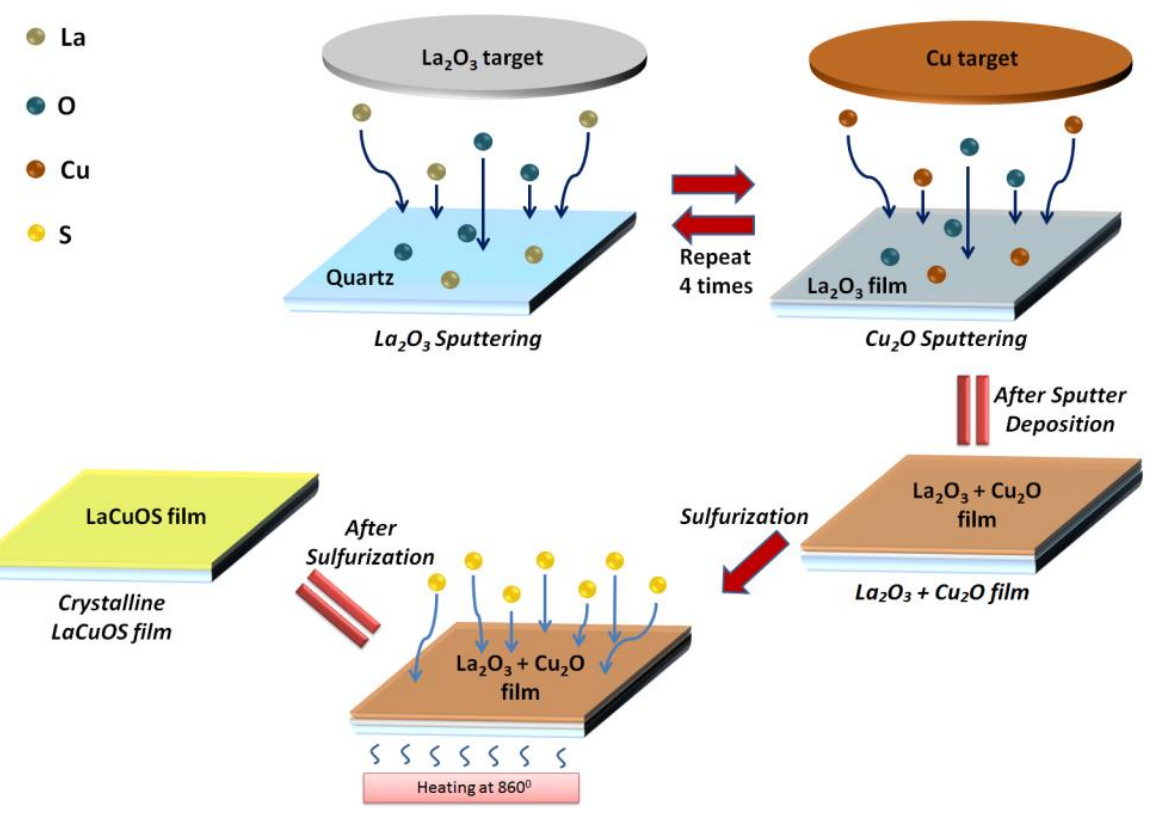

Figure 9. Schematic illustration of the LaCuOS thin film deposition process via sputtering and post-sulfurization. Reproduced with permission from Ref. [196]. Copyright 2018 Elsevier. 
Similar to the fabrication of delafossite thin films, the chemical solution method has the advantages of low cost fabrication, roll-to-roll capability, high throughput, and the possibility for a special nanostructure [108-110]. To explore the possibility of a solution-based fabrication approach, in 2018, Zhang et al. developed the first solution-based method, which is a dip-coating process with a post-sulfurization process to fabricate oxychalcogenide NdCuOS (shown in Figure 10) [189]. As no $\mathrm{H}$-containing compound such as $\mathrm{H}_{2} \mathrm{~S}$ was used during sulfurization, the possibility of hydrogen doping in the thin film was eliminated. Moreover, the $\mathrm{NdCuOS}$ prepared via such a solution method was reported to contain a large $\mathrm{Cu}$ deficiency. The resulting intrinsic $\mathrm{NdCuOS}$ film demonstrated a high p-type conductivity of $6.4 \mathrm{~S} \cdot \mathrm{cm}^{-1}$, and even a higher conductivity of $52.1 \mathrm{~S} \cdot \mathrm{cm}^{-1}$ was achieved after $\mathrm{Mg}$ doping with an acceptable optical transparency higher than 50\%. Moreover, a working p-n junction was made by using this intrinsic $\mathrm{NdCuOS}$ as a p-type terminal, and $\mathrm{ZnO}$ doped with $\mathrm{Al}$ as an n-type terminal. A low turn-on voltage of $1.1 \mathrm{~V}$ and a rather low leakage current of $9.12 \mu \mathrm{A}$ at $-3 \mathrm{~V}$ was obtained for this transparent diode [189].

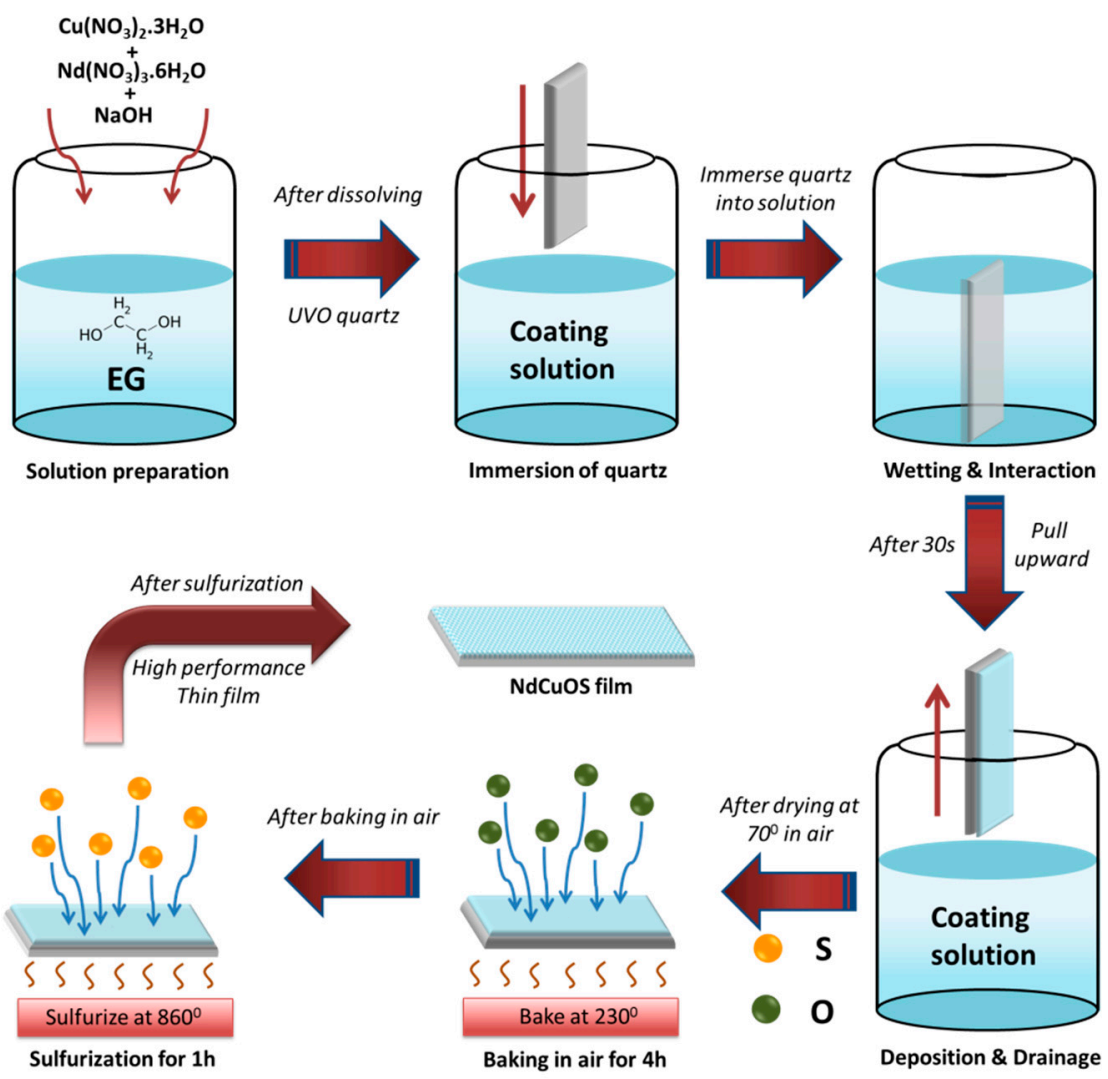

Figure 10. Schematic illustration of the solution-based (dip-coating) process with post-annealing to prepare NdCuOS film. Reproduced with permission from Ref. [189]. Copyright 2018 Elsevier.

\subsection{Copper Oxides}

Copper oxides have two forms: cupric oxide $(\mathrm{CuO})$ and cuprous oxide $\left(\mathrm{Cu}_{2} \mathrm{O}\right)$. $\mathrm{CuO}$ has a tenorite structure, and $\mathrm{Cu}_{2} \mathrm{O}$ has a cubic crystal structure (shown in Figure 11). The optical band gap of $\mathrm{CuO}$ is between $1.9-2.1 \mathrm{eV}$, and that of $\mathrm{Cu}_{2} \mathrm{O}$ is between $2.1-2.6 \mathrm{eV}$, and the low band gaps makes the film non-transparent for a range of the visible light, as the visible light energy reaches $3.1 \mathrm{eV}[197,198]$. They are both reported to be p-type oxides, but the small band gap limits their applications. Thin-film transistor (TFT) is an important application for copper oxide as an active material. Compared with $\mathrm{CuO}, \mathrm{Cu}_{2} \mathrm{O}$ can theoretically exhibit a hole mobility exceeding 100 $\mathrm{cm}^{2} \cdot \mathrm{V}^{-1} \cdot \mathrm{s}^{-1}$, and so it receives more attention [197]. It is recently accepted that the high p-type mobility of $\mathrm{Cu}_{2} \mathrm{O}$ is the result of the band structure of VBM [197]. It has been shown that the p-type 
conductivity of $\mathrm{Cu}_{2} \mathrm{O}$ is from the $\mathrm{Cu}$ vacancies [197]. At the same time, it has also been reported that the presence of oxygen interstitials could contribute to p-type conductivity $[9,199]$. $\mathrm{Cu}_{2} \mathrm{O}$ films can be fabricated by various techniques, which are mainly vacuum-based, such as RFMS [64,200-202], ALD [203-205], and PLD [206-208]. In 2008, Li et al. reported a high Hall mobility of $256 \mathrm{~cm}^{2} \cdot \mathrm{V}^{-1} \cdot \mathrm{s}^{-1}$ in their $\mathrm{Cu}_{2} \mathrm{O}$ thin film deposited by RFMS at a substrate temperature of $600{ }^{\circ} \mathrm{C}$, which is the highest so far for $\mathrm{Cu}_{2} \mathrm{O}$ films [64]. Zou et al. reported a pure phase polycrystalline $\mathrm{Cu}_{2} \mathrm{O}$ by PLD at $500{ }^{\circ} \mathrm{C}$, with a Hall mobility of $107 \mathrm{~cm}^{2} \cdot \mathrm{V}^{-1} \cdot \mathrm{s}^{-1}$ [209]. Jeong and Aydil reported a $\mathrm{Cu}_{2} \mathrm{O}$ film with a Hall mobility over $30 \mathrm{~cm}^{2} \cdot \mathrm{V}^{-1} \cdot \mathrm{s}^{-1}$ by metal-organic chemical vapor deposition (MOCVD) at $400{ }^{\circ} \mathrm{C}$ [210]. Kwon et al. fabricated $\mathrm{Cu}_{2} \mathrm{O}$ films by atomic layer deposition with a Hall mobility of $37 \mathrm{~cm}^{2} \cdot \mathrm{V}^{-1} \cdot \mathrm{s}^{-1}$ [211]. There are limited reports on the solution-fabricated cuprous oxide without vacuum, and its performance is far from satisfactory. Sun et al., Kim et al., and $\mathrm{Yu}$ et al. reported sol-gel methods to fabricate $\mathrm{Cu}_{2} \mathrm{O}$ thin films with a Hall mobility of $8,18.9$, and $31.7 \mathrm{~cm}^{2} \cdot \mathrm{V}^{-1} \cdot \mathrm{s}^{-1}$, respectively [212-214].
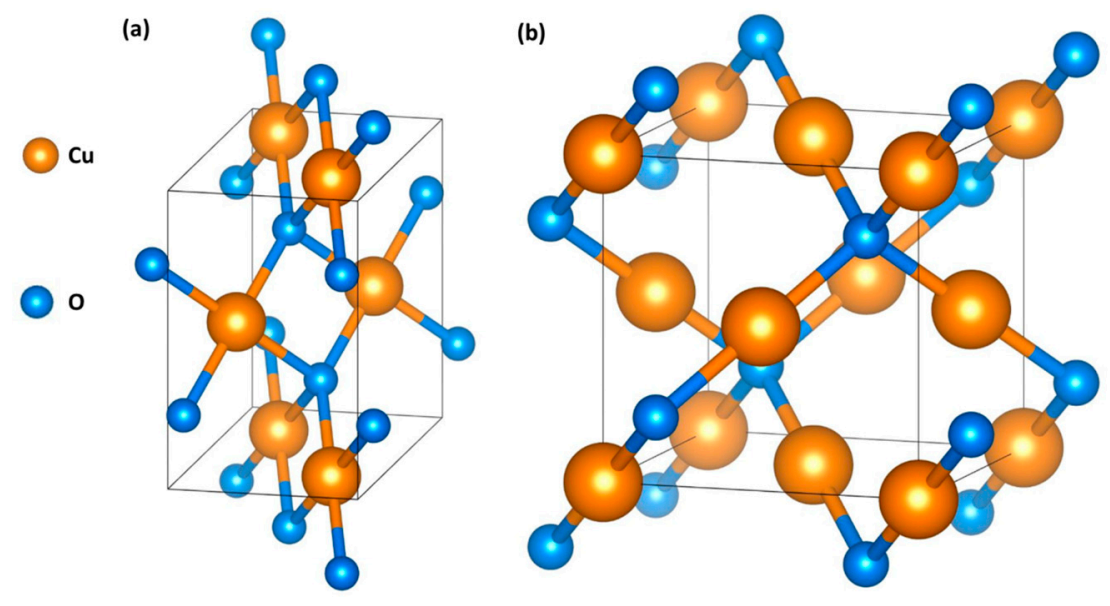

Figure 11. Crystal structure of (a) $\mathrm{CuO}$ and (b) $\mathrm{Cu}_{2} \mathrm{O}$.

In 2008, Matsuzaki et al. reported the first p-type $\mathrm{Cu}_{2} \mathrm{O}$ thin film and TFT device by PLD with a Hall mobility of $90 \mathrm{~cm}^{2} \cdot \mathrm{V}^{-1} \cdot \mathrm{s}^{-1}$ and field-effect mobility of $0.26 \mathrm{~cm}^{2} \cdot \mathrm{V}^{-1} \cdot \mathrm{s}^{-1}$ [215]. Zou et al. also fabricated a p-type $\mathrm{Cu}_{2} \mathrm{O}$ film by PLD and obtained a Hall mobility of $107 \mathrm{~cm}^{2} \cdot \mathrm{V}^{-1} \cdot \mathrm{s}^{-1}$, and the according TFT shows a field-effect mobility of $4.3 \mathrm{~cm}^{2} \cdot \mathrm{V}^{-1} \cdot \mathrm{s}^{-1}$ and an on/off ratio of $10^{6}$, which is the best until now for the copper oxide-based TFTs [209]. Yao et al. reported p-type $\mathrm{Cu}_{2} \mathrm{O}$ TFTs by sputtering, which showed a field-effect mobility of $2.4 \mathrm{~cm}^{2} \cdot \mathrm{V}^{-1} \cdot \mathrm{s}^{-1}$ [216]. In 2013, Kim et al. presented the first solution processed p-type $\mathrm{Cu}_{2} \mathrm{O}$ TFTs with a field-effect mobility of $0.16 \mathrm{~cm}^{2} \cdot \mathrm{V}^{-1} \cdot \mathrm{s}^{-1}$ [213]. Anthopoulos et al. reported $\mathrm{Cu}_{2} \mathrm{O}$ films by solution-based spray pyrolysis and incorporated them into p-type TFTs with a mobility of $0.01 \mathrm{~cm}^{2} \cdot \mathrm{V}^{-1} \cdot \mathrm{s}^{-1}$ and an on/off current ratio of $10^{3}$ [217]. In 2016, Shan et al. fabricated Cu-based oxide TFTs at low-temperature by a solution-processed method with a mobility of $0.78 \mathrm{~cm}^{2} \cdot \mathrm{V}^{-1} \cdot \mathrm{s}^{-1}$ and an on/off current ratio of $10^{5}$ [218]. In 2017, Liu et al. reported low-temperature solution-processed p-type $\mathrm{Cu}_{x} \mathrm{O}$ thin film-based TFTs with $\mathrm{Al}_{2} \mathrm{O}_{3}$ dielectrics, which presented a hole mobility of $2.7 \mathrm{~cm}^{2} \cdot \mathrm{V}^{-1} \cdot \mathrm{s}^{-1}$ and an on/off ratio of $10^{5}$ [219]. While the device performance is encouraging, it should be noted that the rather low band gap or optical transparency would make $\mathrm{Cu}_{2} \mathrm{O}$ have limited applications in transparent devices.

\section{Summary and Perspectives}

In this review, we have illustrated and discussed the material performance of $\mathrm{Cu}$-based oxides (delafossites and copper oxides) and oxychalcogenides ( $\mathrm{LnCuOCh}$ ) for p-type TCO applications. All three types of materials make use of the special feature of $\mathrm{Cu}^{+} 3 d$ orbitals, which are close to $\mathrm{O} 2 p$ orbitals and could hybridize with each other to form a more spatially dispersed VBM, leading to higher hole mobility. Moreover, oxychalcogenides LnCuOS VBM is actually formed by the hybridization of $\mathrm{Cu} 3 d$ orbitals and S $3 p$ orbital states, and this allows for even higher mobility. Over the years, 
many strategies had been developed to improve the hole mobility of the materials. For example, non-isovalent $\mathrm{CuO}$ has been introduced into polycrystalline $\mathrm{CuAlO}_{2}$ film to achieve the hybridization of $\mathrm{Cu}-\mathrm{O}$ dimers in the $\mathrm{CuAlO}_{2}$ lattice, and resulting in a higher Hall mobility [120]. At the same time, many approaches have been investigated to enhance the p-type conductivity by increasing the hole concentration. Different strategies are suitable for different applications, as certain applications such as TFT would prefer TCO with high mobility, while other applications such as HTL in photovoltaics need TCO with high hole concentrations and conductivity.

While many promising results have been generated recently in terms of the p-type conductivity of Cu-based oxides and oxychalcogenides, their mobility and conductivity are still far poorer than their n-type counterparts. In order to further improve their performance, several important issues could be tackled. Firstly, more high-throughput computational studies could be carried out to find potential p-type TCOs with intrinsically higher hole mobility and the ease of p-type doping. Secondly, both cation and anion doping should be investigated in detail, as only very limited studies have been reported for anion doping for $\mathrm{Cu}$-based oxides and oxychalcogenides. Thirdly, more research efforts should be involved in the study of some reported $\mathrm{Cu}$-based oxides and oxychalcogenides with high potential. For instance, $\left[\mathrm{Cu}_{2} \mathrm{~S}_{2}\right]\left[\mathrm{Sr}_{3} \mathrm{Sc}_{2} \mathrm{O}_{5}\right]$ has very high undoped p-type conductivity with two cation sites for doping to further improve both transparency and conductivity, but only one experimental work has been reported for this material. Last but not least, the investigation of bipolar semiconductors should be given more research attention, so that the transparent electronics based on homojunction could be realized. With these four non-exclusive avenues for future p-type TCOs research, we believe that more promising results should be expected.

Funding: This research was funded by Singapore Ministry of Education Academic Research Fund Tier 2 MOE2016-T2-1-049, grant R-284-000-157-112 is appreciated.

Conflicts of Interest: The authors have no conflict of interests.

\section{References}

1. Lewis, B.G.; Paine, D.C. Applications and processing of transparent conducting oxides. MRS Bull. 2000, 25, 22-27. [CrossRef]

2. Fortunato, E.; Barquinha, P.; Martins, R. Oxide semiconductor thin-film transistors: A review of recent advances. Adv. Mater. 2012, 24, 2945-2986. [CrossRef] [PubMed]

3. Fortunato, E.M.; Barquinha, P.M.; Pimentel, A.; Goncalves, A.M.; Marques, A.J.; Pereira, L.M.; Martins, R.F. Fully transparent zno thin-film transistor produced at room temperature. Adv. Mater. 2005, 17, 590-594. [CrossRef]

4. Hoel, C.A.; Mason, T.O.; Gaillard, J.-F.; Poeppelmeier, K.R. Transparent conducting oxides in the $\mathrm{ZnO}-\mathrm{In}_{2} \mathrm{O}_{3}-\mathrm{SnO}_{2}$ system. Chem. Mater. 2010, 22, 3569-3579. [CrossRef]

5. Granqvist, C.G.; Hultåker, A. Transparent and conducting ito films: New developments and applications. Thin Solid Films 2002, 411, 1-5. [CrossRef]

6. Niu, C. Carbon nanotube transparent conducting films. MRS Bull. 2011, 36, 766-773. [CrossRef]

7. Chen, Z.; Li, W.; Li, R.; Zhang, Y.; Xu, G.; Cheng, H. Fabrication of highly transparent and conductive indium-tin oxide thin films with a high figure of merit via solution processing. Langmuir 2013, 29, 13836-13842. [CrossRef]

8. Tripathi, T.S.; Karppinen, M. Atomic layer deposition of p-type semiconducting thin films: A review. Adv. Mater. Interfaces 2017, 4, 1700300. [CrossRef]

9. Raebiger, H.; Lany, S.; Zunger, A. Origins of the p-type nature and cation deficiency in $\mathrm{Cu}_{2} \mathrm{O}$ and related materials. Phys. Rev. B 2007, 76, 045209. [CrossRef]

10. Scanlon, D.O.; Watson, G.W. $\left(\mathrm{Cu}_{2} \mathrm{~S}_{2}\right)\left(\mathrm{Sr}_{3} \mathrm{Sc}_{2} \mathrm{O}_{5}\right)$-A layered, direct band gap, p-type transparent conducting oxychalcogenide: A theoretical analysis. Chem. Mater. 2009, 21, 5435-5442. [CrossRef]

11. Banerjee, A.; Chattopadhyay, K. Recent developments in the emerging field of crystalline p-type transparent conducting oxide thin films. Prog. Cryst. Growth Charact. Mater. 2005, 50, 52-105. [CrossRef] 
12. Hautier, G.; Miglio, A.; Ceder, G.; Rignanese, G.-M.; Gonze, X. Identification and design principles of low hole effective mass p-type transparent conducting oxides. Nat. Commun. 2013, 4, 2292. [CrossRef] [PubMed]

13. Hiramatsu, H.; Kamiya, T.; Tohei, T.; Ikenaga, E.; Mizoguchi, T.; Ikuhara, Y.; Kobayashi, K.; Hosono, H. Origins of hole doping and relevant optoelectronic properties of wide gap p-type semiconductor, lacuose. J. Am. Chem. Soc. 2010, 132, 15060-15067. [CrossRef] [PubMed]

14. Zakutayev, A.; McIntyre, D.; Schneider, G.; Kykyneshi, R.; Keszler, D.; Park, C.-H.; Tate, J. Tunable properties of wide-band gap p-type bacu $\left(\mathrm{Ch}_{1-x} \mathrm{Ch}_{x}{ }^{\prime}\right) \mathrm{F}(\mathrm{Ch}=\mathrm{S}$, Se, Te) thin-film solid solutions. Thin Solid Films 2010, 518, 5494-5500. [CrossRef]

15. Wijeyasinghe, N.; Regoutz, A.; Eisner, F.; Du, T.; Tsetseris, L.; Lin, Y.H.; Faber, H.; Pattanasattayavong, P.; Li, J.; Yan, F. Copper(I) thiocyanate (CuSCN) hole-transport layers processed from aqueous precursor solutions and their application in thin-film transistors and highly efficient organic and organometal halide perovskite solar cells. Adv. Funct. Mater. 2017, 27, 1701818. [CrossRef]

16. Liu, X.; Zhang, N.; Tang, B.; Li, M.; Zhang, Y.-W.; Yu, Z.G.; Gong, H. Highly stable new organic-inorganic hybrid $3 \mathrm{D}$ perovskite $\mathrm{CH}_{3} \mathrm{NH}_{3} \mathrm{PdI}_{3}$ and $2 \mathrm{D}$ perovskite $\left(\mathrm{CH}_{3} \mathrm{NH}_{3}\right)_{3} \mathrm{Pd}_{2} \mathrm{I}_{7}$ : DFT analysis, synthesis, structure, transition behavior, and physical properties. J. Phys. Chem. Lett. 2018, 9, 5862-5872. [CrossRef] [PubMed]

17. Liu, X.; Li, B.; Zhang, N.; Yu, Z.; Sun, K.; Tang, B.; Shi, D.; Yao, H.; Ouyang, J.; Gong, H. Multifunctional RbCl dopants for efficient inverted planar perovskite solar cell with ultra-high fill factor, negligible hysteresis and improved stability. Nano Energy 2018, 53, 567-578. [CrossRef]

18. Liu, X.; Huang, T.J.; Zhang, L.; Tang, B.; Zhang, N.; Shi, D.; Gong, H. Highly stable, new, organic-inorganic perovskite $\left(\mathrm{CH}_{3} \mathrm{NH}_{3}\right)_{2} \mathrm{PdBr}_{4}$ : Synthesis, structure, and physical properties. Chem. Eur. J. 2018, 24, 4991-4998. [CrossRef] [PubMed]

19. Klauk, H.; Zschieschang, U.; Pflaum, J.; Halik, M. Ultralow-power organic complementary circuits. Nature 2007, 445, 745. [CrossRef]

20. Martins, R.; Nathan, A.; Barros, R.; Pereira, L.; Barquinha, P.; Correia, N.; Costa, R.; Ahnood, A.; Ferreira, I.; Fortunato, E. Complementary metal oxide semiconductor technology with and on paper. Adv. Mater. 2011, 23, 4491-4496. [CrossRef]

21. Martins, R.F.; Ahnood, A.; Correia, N.; Pereira, L.M.; Barros, R.; Barquinha, P.M.; Costa, R.; Ferreira, I.M.; Nathan, A.; Fortunato, E.E. Recyclable, flexible, low-power oxide electronics. Adv. Funct. Mater. 2013, 23, 2153-2161. [CrossRef]

22. Wager, J.F.; Hoffman, R. Thin, fast, and flexible. IEEE Spectr. 2011, 48, 42-56. [CrossRef]

23. Kawazoe, H.; Yanagi, H.; Ueda, K.; Hosono, H. Transparent p-type conducting oxides: Design and fabrication of pn heterojunctions. MRS Bull. 2000, 25, 28-36. [CrossRef]

24. Kawazoe, H.; Yasukawa, M.; Hyodo, H.; Kurita, M.; Yanagi, H.; Hosono, H. p-type electrical conduction in transparent thin films of $\mathrm{CuAlO}_{2}$. Nature 1997, 389, 939. [CrossRef]

25. Hu, Z.; Huang, X.; Annapureddy, H.V.; Margulis, C.J. Molecular dynamics study of the temperature-dependent optical kerr effect spectra and intermolecular dynamics of room temperature ionic liquid 1-methoxyethylpyridinium dicyanoamide. J. Phys. Chem. B 2008, 112, 7837-7849. [CrossRef] [PubMed]

26. Gong, H.; Wang, Y.; Luo, Y. Nanocrystalline p-type transparent $\mathrm{Cu}-\mathrm{Al}-\mathrm{O}$ semiconductor prepared by chemical-vapor deposition with $\mathrm{Cu}(\mathrm{acac})_{2}$ and $\mathrm{Al}(\mathrm{acac})_{3}$ precursors. Appl. Phys. Lett. 2000, 76, 3959-3961. [CrossRef]

27. Ohashi, M.; Iida, Y.; Morikawa, H. Preparation of $\mathrm{CuAlO}_{2}$ films by wet chemical synthesis. J. Am. Ceram. Soc. 2002, 85, 270-272. [CrossRef]

28. Banerjee, A.; Kundoo, S.; Chattopadhyay, K. Synthesis and characterization of p-type transparent conducting $\mathrm{CuAlO}_{2}$ thin film by dc sputtering. Thin Solid Films 2003, 440, 5-10. [CrossRef]

29. Mahapatra, S.; Shivashankar, S.A. Low-pressure metal-organic chemical vapor deposition of transparent and p-type conducting $\mathrm{CuCrO}_{2}$ thin films with high conductivity. Chem. Vap. Depos. 2003, 9, 238-240. [CrossRef]

30. Nagarajan, R.; Draeseke, A.; Sleight, A.; Tate, J. p-Type conductivity in $\mathrm{CuCr}_{1-x} \mathrm{Mg}_{x} \mathrm{O}_{2}$ films and powders. J. Appl. Phys. 2001, 89, 8022-8025. [CrossRef]

31. Bywalez, R.; Götzendörfer, S.; Löbmann, P. Structural and physical effects of Mg-doping on p-type $\mathrm{CuCrO}_{2}$ and $\mathrm{CuAl}_{0.5} \mathrm{Cr}_{0.5} \mathrm{O}_{2}$ thin films. J. Mater. Chem. 2010, 20, 6562-6570. [CrossRef]

32. Ueda, K.; Hase, T.; Yanagi, H.; Kawazoe, H.; Hosono, H.; Ohta, H.; Orita, M.; Hirano, M. Epitaxial growth of transparent p-type conducting $\mathrm{CuGaO}_{2}$ thin films on sapphire (001) substrates by pulsed laser deposition. J. Appl. Phys. 2001, 89, 1790-1793. [CrossRef] 
33. Yanagi, H.; Kawazoe, H.; Kudo, A.; Yasukawa, M.; Hosono, H. Chemical design and thin film preparation of p-type conductive transparent oxides. J. Electroceram. 2000, 4, 407-414. [CrossRef]

34. Srinivasan, R.; Chavillon, B.; Doussier-Brochard, C.; Cario, L.; Paris, M.; Gautron, E.; Deniard, P.; Odobel, F.; Jobic, S. Tuning the size and color of the p-type wide band gap delafossite semiconductor $\mathrm{CuGaO}_{2}$ with ethylene glycol assisted hydrothermal synthesis. J. Mater. Chem. 2008, 18, 5647-5653. [CrossRef]

35. Yanagi, H.; Hase, T.; Ibuki, S.; Ueda, K.; Hosono, H. Bipolarity in electrical conduction of transparent oxide semiconductor $\mathrm{CuInO}_{2}$ with delafossite structure. Appl. Phys. Lett. 2001, 78, 1583-1585. [CrossRef]

36. Sasaki, M.; Shimode, M. Fabrication of bipolar $\mathrm{CuInO}_{2}$ with delafossite structure. J. Phys. Chem. Solids 2003, 64, 1675-1679. [CrossRef]

37. Yanagi, H.; Ueda, K.; Ohta, H.; Orita, M.; Hirano, M.; Hosono, H. Fabrication of all oxide transparent p-n homojunction using bipolar $\mathrm{CuInO}_{2}$ semiconducting oxide with delafossite structure. Solid State Commun. 2001, 121, 15-17. [CrossRef]

38. Duan, N.; Sleight, A.; Jayaraj, M.; Tate, J. Transparent p-type conducting $\mathrm{CuScO}_{2+x}$ films. Appl. Phys. Lett. 2000, 77, 1325-1326. [CrossRef]

39. Kakehi, Y.; Nakao, S.; Satoh, K.; Yotsuya, T. Properties of copper-scandium oxide thin films prepared by pulsed laser deposition. Thin Solid Films 2003, 445, 294-298. [CrossRef]

40. Kakehi, Y.; Satoh, K.; Yotsuya, T.; Nakao, S.; Yoshimura, T.; Ashida, A.; Fujimura, N. Epitaxial growth of $\mathrm{CuScO}_{2}$ thin films on sapphire a-plane substrates by pulsed laser deposition. J. Appl. Phys. 2005, 97, 083535. [CrossRef]

41. Manoj, R.; Nisha, M.; Vanaja, K.; Jayaraj, M. Effect of oxygen intercalation on properties of sputtered $\mathrm{CuYO}_{2}$ for potential use as p-type transparent conducting films. Bull. Mater. Sci. 2008, 31, 49-53. [CrossRef]

42. Nagarajan, R.; Duan, N.; Jayaraj, M.; Li, J.; Vanaja, K.; Yokochi, A.; Draeseke, A.; Tate, J.; Sleight, A. p-type conductivity in the delafossite structure. Int. J. Inorg. Mater. 2001, 3, 265-270. [CrossRef]

43. Ingram, B.J.; González, G.B.; Mason, T.O.; Shahriari, D.Y.; Barnabe, A.; Ko, D.; Poeppelmeier, K.R. Transport and defect mechanisms in cuprous delafossites. 1. Comparison of hydrothermal and standard solid-state synthesis in $\mathrm{CuAlO}_{2}$. Chem. Mater. 2004, 16, 5616-5622. [CrossRef]

44. Chen, H.-Y.; Wu, J.-H. Characterization and optoelectronic properties of sol-gel-derived $\mathrm{CuFeO}_{2}$ thin films. Thin Solid Films 2012, 520, 5029-5035. [CrossRef]

45. Chiu, T.-W.; Huang, P.-S. Preparation of delafossite $\mathrm{CuFeO}_{2}$ coral-like powder using a self-combustion glycine nitrate process. Ceram. Int. 2013, 39, S575-S578. [CrossRef]

46. Moharam, M.; Rashad, M.; Elsayed, E.; Abou-Shahba, R. A facile novel synthesis of delafossite $\mathrm{CuFeO}_{2}$ powders. J. Mater. Sci. Mater. Electron. 2014, 25, 1798-1803. [CrossRef]

47. Snure, M.; Tiwari, A. $\mathrm{CuBO}_{2}$ : A p-type transparent oxide. Appl. Phys. Lett. 2007, 91, 092123. [CrossRef]

48. Santra, S.; Das, N.; Chattopadhyay, K. Physical and optical properties of $\mathrm{CuBO}_{2}$ nanopowders synthesized via sol-gel route. In Proceedings of the 16th International Workshop on Physics of Semiconductor Devices, Kanpur, India, 19-22 December 2011; p. 85491W.

49. Iozzi, M.; Vajeeston, P.; Vidya, R.; Ravindran, P.; Fjellvåg, H. Structural and electronic properties of transparent conducting delafossite: A comparison between the $\mathrm{AgBO}_{2}$ and $\mathrm{CuBO}_{2}$ families $(\mathrm{B}=\mathrm{Al}, \mathrm{Ga}$, In and Sc, Y). RSC Adv. 2015, 5, 1366-1377. [CrossRef]

50. Kudo, A.; Yanagi, H.; Hosono, H.; Kawazoe, $\mathrm{H} . \mathrm{SrCu}_{2} \mathrm{O}_{2}$ : A p-type conductive oxide with wide band gap. Appl. Phys. Lett. 1998, 73, 220-222. [CrossRef]

51. Ohta, H.; Kawamura, K.-I.; Orita, M.; Hirano, M.; Sarukura, N.; Hosono, H. Current injection emission from a transparent $\mathrm{p}-\mathrm{n}$ junction composed of $\mathrm{p}-\mathrm{SrCu}_{2} \mathrm{O}_{2} / \mathrm{n}-\mathrm{ZnO}$. Appl. Phys. Lett. 2000, 77, 475-477. [CrossRef]

52. Ohta, H.; Orita, M.; Hirano, M.; Hosono, H. Fabrication and characterization of ultraviolet-emitting diodes composed of transparent p-n heterojunction, p-SrCu${ }_{2} \mathrm{O}_{2}$ and n-ZnO. J. Appl. Phys. 2001, 89, 5720-5725. [CrossRef]

53. Kim, J.; Yamamoto, K.; Iimura, S.; Ueda, S.; Hosono, H. Electron affinity control of amorphous oxide semiconductors and its applicability to organic electronics. Adv. Mater. Interfaces 2018, 5, 1801307. [CrossRef]

54. Zhang, H.; Wang, H.; Chen, W.; Jen, A.K.Y. $\mathrm{CuGaO}_{2}$ : A promising inorganic hole-transporting material for highly efficient and stable perovskite solar cells. Adv. Mater. 2017, 29, 1604984. [CrossRef] [PubMed]

55. Mryasov, O.; Freeman, A. Electronic band structure of indium tin oxide and criteria for transparent conducting behavior. Phys. Rev. B 2001, 64, 233111. [CrossRef] 
56. Scanlon, D.O.; Watson, G.W. Understanding the p-type defect chemistry of $\mathrm{CuCrO}_{2}$. J. Mater. Chem. 2011, 21, 3655-3663. [CrossRef]

57. Ingram, B.; Mason, T.; Asahi, R.; Park, K.; Freeman, A. Electronic structure and small polaron hole transport of copper aluminate. Phys. Rev. B 2001, 64, 155114. [CrossRef]

58. Shin, D.; Foord, J.; Egdell, R.; Walsh, A. Electronic structure of $\mathrm{CuCrO}_{2}$ thin films grown on $\mathrm{Al}_{2} \mathrm{O}_{3}(001)$ by oxygen plasma assisted molecular beam epitaxy. J. Appl. Phys. 2012, 112, 113718. [CrossRef]

59. Zhang, Y.; Qiao, Z.-P.; Chen, X.-M. Microwave-assisted elemental direct reaction route to nanocrystalline copper chalcogenides cuse and $\mathrm{Cu}_{2}$ Te. J. Mater. Chem. 2002, 12, 2747-2748. [CrossRef]

60. Liu, M.L.; Wu, L.B.; Huang, F.Q.; Chen, L.D.; Ibers, J.A. Syntheses, crystal and electronic structure, and some optical and transport properties of lncuote $(\mathrm{Ln}=\mathrm{La}, \mathrm{Ce}, \mathrm{Nd})$. J. Solid State Chem. 2007, 180, 62-69. [CrossRef]

61. Ueda, K.; Inoue, S.; Hosono, H.; Sarukura, N.; Hirano, M. Room-temperature excitons in wide-gap layered-oxysulfide semiconductor: Lacuos. Appl. Phys. Lett. 2001, 78, 2333-2335. [CrossRef]

62. Ueda, K.; Hiramatsu, H.; Ohta, H.; Hirano, M.; Kamiya, T.; Hosono, H. Single-atomic-layered quantum wells built in wide-gap semiconductors $\mathrm{LnCuOCh}(\mathrm{Ln}=$ lanthanide, $\mathrm{Ch}=$ chalcogen). Phys. Rev. B 2004, 69, 155305. [CrossRef]

63. Hiramatsu, H.; Ueda, K.; Ohta, H.; Hirano, M.; Kikuchi, M.; Yanagi, H.; Kamiya, T.; Hosono, H. Heavy hole doping of epitaxial thin films of a wide gap p-type semiconductor, lacuose, and analysis of the effective mass. Appl. Phys. Lett. 2007, 91, 012104. [CrossRef]

64. Li, B.; Akimoto, K.; Shen, A. Growth of $\mathrm{Cu}_{2} \mathrm{O}$ thin films with high hole mobility by introducing a low-temperature buffer layer. J. Cryst. Growth 2009, 311, 1102-1105. [CrossRef]

65. De Jongh, P.; Vanmaekelbergh, D.; Kelly, J. Cu, O: Electrodeposition and characterization. Chem. Mater. 1999, 11, 3512-3517. [CrossRef]

66. Wang, Y.; Miska, P.; Pilloud, D.; Horwat, D.; Mücklich, F.; Pierson, J.-F. Transmittance enhancement and optical band gap widening of $\mathrm{Cu}_{2} \mathrm{O}$ thin films after air annealing. J. Appl. Phys. 2014, 115, 073505. [CrossRef]

67. Nian, J.-N.; Hu, C.-C.; Teng, H. Electrodeposited p-type $\mathrm{Cu}_{2} \mathrm{O}$ for $\mathrm{H}_{2}$ evolution from photoelectrolysis of water under visible light illumination. Int. J. Hydrog. Energy 2008, 33, 2897-2903. [CrossRef]

68. Ruiz, E.; Alvarez, S.; Alemany, P.; Evarestov, R.A. Electronic structure and properties of Cu, O. Phys. Rev. B 1997, 56, 7189. [CrossRef]

69. Scanlon, D.O.; Morgan, B.J.; Watson, G.W.; Walsh, A. Acceptor levels in p-type Cu $2 \mathrm{O}$ : Rationalizing theory and experiment. Phys. Rev. Lett. 2009, 103, 096405. [CrossRef]

70. Ishiguro, T.; Kitazawa, A.; Mizutani, N.; Kato, M. Single-crystal growth and crystal structure refinement of $\mathrm{CuAlO}_{2}$. J. Solid State Chem. 1981, 40, 170-174. [CrossRef]

71. Marquardt, M.A.; Ashmore, N.A.; Cann, D.P. Crystal chemistry and electrical properties of the delafossite structure. Thin Solid Films 2006, 496, 146-156. [CrossRef]

72. Wei, R.; Tang, X.; Hu, L.; Yang, J.; Zhu, X.; Song, W.; Dai, J.; Zhu, X.; Sun, Y. Facile chemical solution synthesis of p-type delafossite Ag-based transparent conducting $\mathrm{AgCrO}_{2}$ films in an open condition. J. Mater. Chem. C 2017, 5, 1885-1892. [CrossRef]

73. Benko, F.; Koffyberg, F. The optical interband transitions of the semiconductor $\mathrm{CuGaO}_{2}$. Physica Status Solidi (a) 1986, 94, 231-234. [CrossRef]

74. Vanaja, K.; Ajimsha, R.; Asha, A.; Jayaraj, M. p-type electrical conduction in $\alpha-\mathrm{AgGaO}_{2}$ delafossite thin films. Appl. Phys. Lett. 2006, 88, 212103. [CrossRef]

75. Kandpal, H.C.; Seshadri, R. First-principles electronic structure of the delafossites $\mathrm{ABO}_{2}(\mathrm{~A}=\mathrm{Cu}, \mathrm{Ag}, \mathrm{Au}$; $\mathrm{B}=\mathrm{Al}, \mathrm{Ga}, \mathrm{Sc}, \mathrm{In}, \mathrm{Y})$ : Evolution of $\mathrm{d}^{10}-\mathrm{d}^{10}$ interactions. Solid State Sci. 2002, 4, 1045-1052. [CrossRef]

76. Huda, M.N.; Yan, Y.; Walsh, A.; Wei, S.-H.; Al-Jassim, M.M. Group-IIIA versus IIIB delafossites: Electronic structure study. Phys. Rev. B 2009, 80, 035205. [CrossRef]

77. Pellicer-Porres, J.; Segura, A.; Gilliland, A.; Munoz, A.; Rodríguez-Hernández, P.; Kim, D.; Lee, M.; Kim, T. On the band gap of $\mathrm{CuAlO}_{2}$ delafossite. Appl. Phys. Lett. 2006, 88, 181904. [CrossRef]

78. Gilliland, S.; Pellicer-Porres, J.; Segura, A.; Muñoz, A.; Rodríguez-Hernández, P.; Kim, D.; Lee, M.; Kim, T. Electronic structure of $\mathrm{CuAlO}_{2}$ and $\mathrm{CuScO}_{2}$ delafossites under pressure. Phys. Status Solidi (b) 2007, 244, 309-314. [CrossRef]

79. Jayalakshmi, V.; Murugan, R.; Palanivel, B. Electronic and structural properties of $\mathrm{CuMO}_{2}(\mathrm{M}=\mathrm{Al}, \mathrm{Ga}, \mathrm{In})$. J. Alloy. Compd. 2005, 388, 19-22. [CrossRef] 
80. Buljan, A.; Alemany, P.; Ruiz, E. Electronic structure and bonding in $\mathrm{CuMO}_{2}(\mathrm{M}=\mathrm{Al}, \mathrm{Ga}, \mathrm{Y})$ delafossite-type oxides: An ab initio study. J. Phys. Chem. B 1999, 103, 8060-8066. [CrossRef]

81. Schiavo, E.; Latouche, C.; Barone, V.; Crescenzi, O.; Muñoz-García, A.B.; Pavone, M. An ab initio study of $\mathrm{Cu}$-based delafossites as an alternative to nickel oxide in photocathodes: Effects of Mg-doping and surface electronic features. Phys. Chem. Chem. Phys. 2018, 20, 14082-14089. [CrossRef] [PubMed]

82. Sakulkalavek, A.; Sakdanuphab, R. Power factor improvement of delafossite $\mathrm{CuAlO}_{2}$ by liquid-phase sintering with $\mathrm{Ag}_{2} \mathrm{O}$ addition. Mater. Sci. Semicond. Process. 2016, 56, 313-323. [CrossRef]

83. Li, J.; Sleight, A.; Jones, C.; Toby, B. Trends in negative thermal expansion behavior for AMO2 (A = Cu Or $\mathrm{Ag} ; \mathrm{M}=\mathrm{Al}$, Sc, In, or La) compounds with the delafossite structure. J. Solid State Chem. 2005, 178, 285-294. [CrossRef]

84. Tsuboi, N.; Hoshino, T.; Ohara, H.; Suzuki, T.; Kobayashi, S.; Kato, K.; Kaneko, F. Control of luminescence and conductivity of delafossite-type $\mathrm{CuYO}_{2}$ by substitution of rare earth cation $(\mathrm{Eu}, \mathrm{Tb})$ and/or Ca cation for Y cation. J. Phys. Chem. Solids 2005, 66, 2134-2138. [CrossRef]

85. Ruttanapun, C. Optical and electronic properties of delafossite $\mathrm{CuBO}_{2}$ p-type transparent conducting oxide. J. Appl. Phys. 2013, 114, 113108. [CrossRef]

86. Scanlon, D.O.; Walsh, A.; Watson, G.W. Understanding the p-type conduction properties of the transparent conducting oxide $\mathrm{CuBO}_{2}$ : A density functional theory analysis. Chem. Mater. 2009, 21, 4568-4576. [CrossRef]

87. Scanlon, D.O.; Watson, G.W. Conductivity limits in $\mathrm{CuAlO}_{2}$ from screened-hybrid density functional theory. J. Phys. Chem. Lett. 2010, 1, 3195-3199. [CrossRef]

88. Benko, F.; Koffyberg, F. Opto-electronic properties of $\mathrm{CuAlO}_{2}$. J. Phys. Chem. Solids 1984, 45, 57-59. [CrossRef]

89. Fang, M.; He, H.; Lu, B.; Zhang, W.; Zhao, B.; Ye, Z.; Huang, J. Optical properties of p-type CuAlO 2 thin film grown by rf magnetron sputtering. Appl. Surf. Sci. 2011, 257, 8330-8333. [CrossRef]

90. Tsuboi, N.; Takahashi, Y.; Kobayashi, S.; Shimizu, H.; Kato, K.; Kaneko, F. Delafossite $\mathrm{CuAlO}_{2}$ films prepared by reactive sputtering using $\mathrm{Cu}$ and $\mathrm{Al}$ targets. J. Phys. Chem. Solids 2003, 64, 1671-1674. [CrossRef]

91. Stauber, R.; Perkins, J.D.; Parilla, P.A.; Ginley, D.S. Thin film growth of transparent p-type $\mathrm{CuAlO}_{2}$. Electrochem. Solid-State Lett. 1999, 2, 654-656. [CrossRef]

92. Tripathi, T.; Niemelä, J.-P.; Karppinen, M. Atomic layer deposition of transparent semiconducting oxide $\mathrm{CuCrO}_{2}$ thin films. J. Mater. Chem. C 2015, 3, 8364-8371. [CrossRef]

93. Tripathi, T.S.; Karppinen, M. Enhanced p-type transparent semiconducting characteristics for ALD-grown Mg-substituted $\mathrm{CuCrO}_{2}$ thin films. Adv. Electron. Mater. 2017, 3, 1600341. [CrossRef]

94. Gao, S.; Zhao, Y.; Gou, P.; Chen, N.; Xie, Y. Preparation of $\mathrm{CuAlO}_{2}$ nanocrystalline transparent thin films with high conductivity. Nanotechnology 2003, 14, 538. [CrossRef]

95. Sheets, W.C.; Mugnier, E.; Barnabe, A.; Marks, T.J.; Poeppelmeier, K.R. Hydrothermal synthesis of delafossite-type oxides. Chem. Mater. 2006, 18, 7-20. [CrossRef]

96. Götzendörfer, S.; Polenzky, C.; Ulrich, S.; Löbmann, P. Preparation of $\mathrm{CuAlO}_{2}$ and $\mathrm{CuCrO}_{2}$ thin films by sol-gel processing. Thin Solid Films 2009, 518, 1153-1156. [CrossRef]

97. Prévot, M.S.; Li, Y.; Guijarro, N.; Sivula, K. Improving charge collection with delafossite photocathodes: A host-guest $\mathrm{CuAlO}_{2} / \mathrm{CuFeO}_{2}$ approach. J. Mater. Chem. A 2016, 4, 3018-3026. [CrossRef]

98. Chiu, S.; Huang, J. Characterization of p-type $\mathrm{CuAlO}_{2}$ thin films grown by chemical solution deposition. Surf. Coat. Technol. 2013, 231, 239-242. [CrossRef]

99. Phani, P.S.; Vishnukanthan, V.; Sundararajan, G. Effect of heat treatment on properties of cold sprayed nanocrystalline copper alumina coatings. Acta Mater. 2007, 55, 4741-4751. [CrossRef]

100. Bouzidi, C.; Bouzouita, H.; Timoumi, A.; Rezig, B. Fabrication and characterization of $\mathrm{CuAlO}_{2}$ transparent thin films prepared by spray technique. Mater. Sci. Eng. B 2005, 118, 259-263. [CrossRef]

101. Grilli, M.; Menchini, F.; Dikonimos, T.; Nunziante, P.; Pilloni, L.; Yilmaz, M.; Piegari, A.; Mittiga, A. Effect of growth parameters on the properties of RF-sputtered highly conductive and transparent p-type $\mathrm{NiO}_{x}$ films. Semicond. Sci. Technol. 2016, 31, 055016. [CrossRef]

102. Lu, Y.; He, Y.; Yang, B.; Polity, A.; Volbers, N.; Neumann, C.; Hasselkamp, D.; Meyer, B. RF reactive sputter deposition and characterization of transparent $\mathrm{CuAlO}_{2}$ thin films. Phys. Status Solidic 2006, 3, 2895-2898. [CrossRef]

103. Zhang, K.H.; Xi, K.; Blamire, M.G.; Egdell, R.G. P-type transparent conducting oxides. J. Phys. Condens. Matter 2016, 28, 383002. [CrossRef] [PubMed] 
104. Xiao, B.; Ye, Z.; Zhang, Y.; Zeng, Y.; Zhu, L.; Zhao, B. Fabrication of p-type Li-doped ZnO films by pulsed laser deposition. Appl. Surf. Sci. 2006, 253, 895-897. [CrossRef]

105. Ryu, Y.; Kim, W.; White, H. Fabrication of homostructural ZnO p-n junctions. J. Cryst. Growth 2000, 219, 419-422. [CrossRef]

106. Leskelä, M.; Ritala, M. Atomic layer deposition chemistry: Recent developments and future challenges. Angew. Chem. Int. Ed. 2003, 42, 5548-5554. [CrossRef] [PubMed]

107. Miikkulainen, V.; Leskelä, M.; Ritala, M.; Puurunen, R.L. Crystallinity of inorganic films grown by atomic layer deposition: Overview and general trends. J. Appl. Phys. 2013, 113, 2. [CrossRef]

108. Das, B.; Renaud, A.; Volosin, A.M.; Yu, L.; Newman, N.; Seo, D.-K. Nanoporous delafossite CuAlO $\mathrm{Cl}_{2}$ from inorganic/polymer double gels: A desirable high-surface-area p-type transparent electrode material. Inorg. Chem. 2015, 54, 1100-1108. [CrossRef] [PubMed]

109. Nie, S.; Liu, A.; Meng, Y.; Shin, B.; Liu, G.; Shan, F. Solution-processed ternary p-type $\mathrm{CuCrO}_{2}$ semiconductor thin films and their application in transistors. J. Mater. Chem. C 2018, 6, 1393-1398. [CrossRef]

110. Ginley, D.; Roy, B.; Ode, A.; Warmsingh, C.; Yoshida, Y.; Parilla, P.; Teplin, C.; Kaydanova, T.; Miedaner, A.; Curtis, C. Non-vacuum and pld growth of next generation tco materials. Thin Solid Films 2003, 445, 193-198. [CrossRef]

111. Yanagi, H.; Inoue, S.-I.; Ueda, K.; Kawazoe, H.; Hosono, H.; Hamada, N. Electronic structure and optoelectronic properties of transparent p-type conducting $\mathrm{CuAlO}_{2}$. J. Appl. Phys. 2000, 88, 4159-4163. [CrossRef]

112. Aston, D.; Payne, D.; Green, A.; Egdell, R.; Law, D.; Guo, J.; Glans, P.; Learmonth, T.; Smith, K. High-resolution $\mathrm{X}$-ray spectroscopic study of the electronic structure of the prototypical p-type transparent conducting oxide $\mathrm{CuAlO}$. Phys. Rev. B 2005, 72, 195115. [CrossRef]

113. Katayama-Yoshida, H.; Koyanagi, T.; Funashima, H.; Harima, H.; Yanase, A. Engineering of nested fermi surface and transparent conducting p-type delafossite $\mathrm{CuAlO}_{2}$ : Possible lattice instability or transparent superconductivity? Solid State Commun. 2003, 126, 135-139. [CrossRef]

114. Koyanagi, T.; Harima, H.; Yanase, A.; Katayama-Yoshida, H. Materials design of p-type transparent conducting oxides of delafossite $\mathrm{CuAlO}_{2}$ by super-cell FLAPW method. J. Phys. Chem. Solids 2003, 64, 1443-1446. [CrossRef]

115. Dong, G.; Zhang, M.; Lan, W.; Dong, P.; Yan, H. Structural and physical properties of Mg-doped CuAlO thin films. Vacuum 2008, 82, 1321-1324. [CrossRef]

116. Durá, O.; Boada, R.; Rivera-Calzada, A.; León, C.; Bauer, E.; de la Torre, M.L.; Chaboy, J. Transport, electronic, and structural properties of nanocrystalline $\mathrm{CuAlO}_{2}$ delafossites. Phys. Rev. B 2011, 83, 045202. [CrossRef]

117. Lee, M.; Kim, T.; Kim, D. Anisotropic electrical conductivity of delafossite-type $\mathrm{CuAlO}_{2}$ laminar crystal. Appl. Phys. Lett. 2001, 79, 2028-2030. [CrossRef]

118. Tate, J.; Ju, H.; Moon, J.; Zakutayev, A.; Richard, A.; Russell, J.; McIntyre, D. Origin of p-type conduction in single-crystal $\mathrm{CuAlO}_{2}$. Phys. Rev. B 2009, 80, 165206. [CrossRef]

119. Luo, J.; Lin, Y.-J.; Hung, H.-C.; Liu, C.-J.; Yang, Y.-W. Tuning the formation of p-type defects by peroxidation of $\mathrm{CuAlO}_{2}$ films. J. Appl. Phys. 2013, 114, 033712.

120. Yao, Z.; He, B.; Zhang, L.; Zhuang, C.; Ng, T.; Liu, S.; Vogel, M.; Kumar, A.; Zhang, W.; Lee, C. Energy band engineering and controlled p-type conductivity of $\mathrm{CuAlO}_{2}$ thin films by nonisovalent $\mathrm{Cu}-\mathrm{O}$ alloying. Appl. Phys. Lett. 2012, 100, 062102. [CrossRef]

121. Rastogi, A.; Lim, S.; Desu, S. Structure and optoelectronic properties of spray deposited $\mathrm{Mg}$ doped p-CuCrO semiconductor oxide thin films. J. Appl. Phys. 2008, 104, 023712. [CrossRef]

122. Chen, H.-Y.; Yang, C.-C. Transparent p-type $\mathrm{Zn}$-doped $\mathrm{CuCrO}_{2}$ films by sol-gel processing. Surf. Coat. Technol. 2013, 231, 277-280. [CrossRef]

123. Dong, G.; Zhang, M.; Zhao, X.; Yan, H.; Tian, C.; Ren, Y. Improving the electrical conductivity of $\mathrm{CuCrO}_{2}$ thin film by n doping. Appl. Surf. Sci. 2010, 256, 4121-4124. [CrossRef]

124. Ahmadi, M.; Asemi, M.; Ghanaatshoar, M. $\mathrm{Mg}$ and $\mathrm{N}$ co-doped $\mathrm{CuCrO}_{2}$ : A record breaking p-type TCO. Appl. Phys. Lett. 2018, 113, 242101. [CrossRef]

125. Crêpellière, J.; Popa, P.L.; Bahlawane, N.; Leturcq, R.; Werner, F.; Siebentritt, S.; Lenoble, D. Transparent conductive $\mathrm{CuCrO}_{2}$ thin films deposited by pulsed injection metal organic chemical vapor deposition: Up-scalable process technology for an improved transparency/conductivity trade-off. J. Mater. Chem. C 2016, 4, 4278-4287. [CrossRef] 
126. Popa, P.L.; Crepelliere, J.; Nukala, P.; Leturcq, R.; Lenoble, D. Invisible electronics: Metastable Cu-vacancies chain defects for highly conductive p-type transparent oxide. Appl. Mater. Today 2017, 9, 184-191. [CrossRef]

127. Farrell, L.; Norton, E.; O’Dowd, B.; Caffrey, D.; Shvets, I.; Fleischer, K. Spray pyrolysis growth of a high figure of merit, nano-crystalline, p-type transparent conducting material at low temperature. Appl. Phys. Lett. 2015, 107, 031901. [CrossRef]

128. Papadopoulou, E.; Viskadourakis, Z.; Pennos, A.; Huyberechts, G.; Aperathitis, E. The effect of deposition parameters on the properties of $\mathrm{SrCu}_{2} \mathrm{O}_{2}$ films fabricated by pulsed laser deposition. Thin Solid Films 2008, 516, 1449-1452. [CrossRef]

129. Arnold, T.; Payne, D.; Bourlange, A.; Hu, J.; Egdell, R.; Piper, L.; Colakerol, L.; De Masi, A.; Glans, P.-A.; Learmonth, T. X-ray spectroscopic study of the electronic structure of $\mathrm{CuCrO}_{2}$. Phys. Rev. B 2009, 79, 075102. [CrossRef]

130. Scanlon, D.O.; Walsh, A.; Morgan, B.J.; Watson, G.W.; Payne, D.J.; Egdell, R.G. Effect of cr substitution on the electronic structure of $\mathrm{CuAl}_{1-x} \mathrm{Cr}_{x} \mathrm{O}_{2}$. Phys. Rev. B 2009, 79, 035101. [CrossRef]

131. Scanlon, D.O.; Godinho, K.G.; Morgan, B.J.; Watson, G.W. Understanding conductivity anomalies in $\mathrm{Cu}^{\mathrm{I}}$-based delafossite transparent conducting oxides: Theoretical insights. J. Chem. Phys. 2010, 132, 024707. [CrossRef]

132. Zheng, S.; Jiang, G.; Su, J.; Zhu, C. The structural and electrical property of $\mathrm{CuCr}_{1-x} \mathrm{Ni}_{x} \mathrm{O}_{2}$ delafossite compounds. Mater. Lett. 2006, 60, 3871-3873. [CrossRef]

133. Kaya, I.C.; Sevindik, M.A.; Akyıldız, H. Characteristics of Fe-and $\mathrm{Mg}$-doped $\mathrm{CuCrO}_{2}$ nanocrystals prepared by hydrothermal synthesis. J. Mater. Sci. Mater. Electron. 2016, 27, 2404-2411. [CrossRef]

134. Okuda, T.; Jufuku, N.; Hidaka, S.; Terada, N. Magnetic, transport, and thermoelectric properties of the delafossite oxides $\mathrm{CuCr}_{1-x} \mathrm{Mg}_{x} \mathrm{O}_{2}(0 \leq x \leq 0.04)$. Phys. Rev. B 2005, 72, 144403. [CrossRef]

135. Madre, M.; Torres, M.; Gomez, J.; Diez, J.; Sotelo, A. Effect of alkaline earth dopant on density, mechanical, and electrical properties of $\mathrm{Cu}_{0.97} \mathrm{AE}_{0.03} \mathrm{CrO}_{2}(\mathrm{AE}=\mathrm{Mg}, \mathrm{Ca}, \mathrm{Sr}$, and $\mathrm{Ba})$ delafossite oxide. J. Aust. Ceram. Soc. 2019, 55, 257-263. [CrossRef]

136. Xu, Y.; Nie, G.-Z.; Zou, D.; Tang, J.-W.; Ao, Z. N-Mg dual-acceptor co-doping in $\mathrm{CuCrO}_{2}$ studied by first-principles calculations. Phys. Lett. A 2016, 380, 3861-3865. [CrossRef]

137. Mandal, P.; Mazumder, N.; Saha, S.; Ghorai, U.K.; Roy, R.; Das, G.C.; Chattopadhyay, K.K. A scheme of simultaneous cationic-anionic substitution in $\mathrm{CuCrO}_{2}$ for transparent and superior p-type transport. J. Phys. D Appl. Phys. 2016, 49, 275109. [CrossRef]

138. Monteiro, J.F.H.L.; Monteiro, F.C.; Jurelo, A.R.; Mosca, D.H. Conductivity in (Ag,Mg)-doped delafossite oxide $\mathrm{CuCrO}_{2}$. Ceram. Int. 2018, 44,14101-14107. [CrossRef]

139. Wang, J.; Daunis, T.B.; Cheng, L.; Zhang, B.; Kim, J.; Hsu, J.W. Combustion synthesis of p-type transparent conducting $\mathrm{CuCro}_{2+x}$ and Cu: Cro ${ }_{x}$ thin films at $180{ }^{\circ} \mathrm{C}$. ACS Appl. Mater. Interfaces 2018, 10, 3732-3738. [CrossRef]

140. Jun, T.; Kim, J.; Sasase, M.; Hosono, H. Material design of p-type transparent amorphous semiconductor, Cu-Sn-I. Adv. Mater. 2018, 30, 1706573. [CrossRef] [PubMed]

141. Li, X.R.; Han, M.J.; Wu, J.D.; Shan, C.; Hu, Z.G.; Zhu, Z.Q.; Chu, J.H. Low voltage tunneling magnetoresistance in $\mathrm{CuCrO}_{2}$-based semiconductor heterojunctions at room temperature. J. Appl. Phys. 2014, 116, 223701. [CrossRef]

142. Wang, J.; Lee, Y.-J.; Hsu, J.W. Sub-10 nm copper chromium oxide nanocrystals as a solution processed p-type hole transport layer for organic photovoltaics. J. Mater. Chem. C 2016, 4, 3607-3613. [CrossRef]

143. Ngo, T.; Palstra, T.; Blake, G. Crystallite size dependence of thermoelectric performance of $\mathrm{CuCrO}_{2}$. RSC Adv. 2016, 6, 91171-91178. [CrossRef]

144. Ono, Y.; Satoh, K.-I.; Nozaki, T.; Kajitani, T. Structural, magnetic and thermoelectric properties of delafossite-type oxide, $\mathrm{CuCr}_{1-x} \mathrm{Mg}_{x} \mathrm{O}_{2}(0 \leq x \leq 0.05)$. Jpn. J. Appl. Phys. 2007, 46, 1071. [CrossRef]

145. Li, X.; Han, M.; Zhang, X.; Shan, C.; Hu, Z.; Zhu, Z.; Chu, J. Temperature-dependent band gap, interband transitions, and exciton formation in transparent p-type delafossite $\mathrm{CuCr}_{1-x} \mathrm{Mg}_{x} \mathrm{O}_{2}$ films. Phys. Rev. B 2014, 90, 035308. [CrossRef]

146. Yokobori, T.; Okawa, M.; Konishi, K.; Takei, R.; Katayama, K.; Oozono, S.; Shinmura, T.; Okuda, T.; Wadati, H.; Sakai, E. Electronic structure of the hole-doped delafossite oxides $\mathrm{CuCr}_{1-x} \mathrm{Mg}_{x} \mathrm{O}_{2}$. Phys. Rev. B 2013, 87, 195124. [CrossRef] 
147. Li, D.; Fang, X.; Deng, Z.; Zhou, S.; Tao, R.; Dong, W.; Wang, T.; Zhao, Y.; Meng, G.; Zhu, X. Electrical, optical and structural properties of $\mathrm{CuCrO}_{2}$ films prepared by pulsed laser deposition. J. Phys. D Appl. Phys. 2007, 40, 4910. [CrossRef]

148. Benko, F.; Koffyberg, F. Preparation and opto-electronic properties of semiconducting $\mathrm{CuCrO}_{2}$. Mater. Res. Bull. 1986, 21, 753-757. [CrossRef]

149. Nie, X.; Wei, S.-H.; Zhang, S. Bipolar doping and band-gap anomalies in delafossite transparent conductive oxides. Phys. Rev. Lett. 2002, 88, 066405. [CrossRef]

150. Santra, S.; Das, N.; Chattopadhyay, K. Sol-gel synthesis and characterization of wide band gap p-type nanocrystalline $\mathrm{CuBO}_{2}$. Mater. Lett. 2013, 92, 198-201. [CrossRef]

151. Santra, S.; Das, N.; Chattopadhyay, K. Wide band gap p-type nanocrystalline $\mathrm{CuBO}_{2}$ as a novel UV photocatalyst. Mater. Res. Bull. 2013, 48, 2669-2677. [CrossRef]

152. Santra, S.; Das, N.S.; Chattopadhyay, K.K. $\mathrm{CuBO}_{2}$ : A new photoconducting material. AIP Conf. Proc. 2013, 1536, 723-724. [CrossRef]

153. Renaud, A.; Chavillon, B.; Le Pleux, L.; Pellegrin, Y.; Blart, E.; Boujtita, M.; Pauporte, T.; Cario, L.; Jobic, S.; Odobel, F. $\mathrm{CuGaO}_{2}$ : A promising alternative for $\mathrm{NiO}$ in p-type dye solar cells. J. Mater. Chem. 2012, 22, 14353-14356. [CrossRef]

154. Xu, Z.; Xiong, D.; Wang, H.; Zhang, W.; Zeng, X.; Ming, L.; Chen, W.; Xu, X.; Cui, J.; Wang, M. Remarkable photocurrent of p-type dye-sensitized solar cell achieved by size controlled $\mathrm{CuGaO}_{2}$ nanoplates. J. Mater. Chem. A 2014, 2, 2968-2976. [CrossRef]

155. Yu, M.; Natu, G.; Ji, Z.; Wu, Y. p-type dye-sensitized solar cells based on delafossite $\mathrm{CuGaO}_{2}$ nanoplates with saturation photovoltages exceeding $460 \mathrm{mV}$. J. Phys. Chem. Lett. 2012, 3, 1074-1078. [CrossRef] [PubMed]

156. Renaud, A.l.; Cario, L.; Deniard, P.; Gautron, E.; Rocquefelte, X.; Pellegrin, Y.; Blart, E.; Odobel, F.; Jobic, S. Impact of $\mathrm{Mg}$ doping on performances of $\mathrm{CuGaO}_{2}$ based p-type dye-sensitized solar cells. J. Phys. Chem. C 2013, 118, 54-59. [CrossRef]

157. Zhang, S.; Wei, S.-H.; Zunger, A. A phenomenological model for systematization and prediction of doping limits in II-VI and I-III-VI 2 compounds. J. Appl. Phys. 1998, 83, 3192-3196. [CrossRef]

158. Zhang, S.; Wei, S.-H.; Zunger, A. Microscopic origin of the phenomenological equilibrium "doping limit rule" in n-type III-V semiconductors. Phys. Rev. Lett. 2000, 84, 1232. [CrossRef]

159. Zhang, S.; Wei, S.-H.; Zunger, A. Intrinsic n-type versus p-type doping asymmetry and the defect physics of ZnO. Phys. Rev. B 2001, 63, 075205. [CrossRef]

160. Arai, T.; Iimura, S.; Kim, J.; Toda, Y.; Ueda, S.; Hosono, H. Chemical design and example of transparent bipolar semiconductors. J. Am. Chem. Soc. 2017, 139, 17175-17180. [CrossRef]

161. Cava, R.; Zandbergen, H.; Ramirez, A.; Takagi, H.; Chen, C.; Krajewski, J.; Peck, W., Jr.; Waszczak, J.; Meigs, G.; Roth, R. $\mathrm{LaCuO}_{25+x}$ and $\mathrm{YCuO}_{2.5+x}$ delafossites: Materials with triangular $\mathrm{Cu}^{2+\delta}$ planes. J. Solid State Chem. 1993, 104, 437-452. [CrossRef]

162. Ingram, B.J.; Harder, B.J.; Hrabe, N.W.; Mason, T.O.; Poeppelmeier, K.R. Transport and defect mechanisms in cuprous delafossites. 2. $\mathrm{CuScO}_{2}$ and $\mathrm{CuYO}_{2}$. Chem. Mater. 2004, 16, 5623-5629. [CrossRef]

163. Ohta, H.; Orita, M.; Hirano, M.; Yagi, I.; Ueda, K.; Hosono, H. Electronic structure and optical properties of $\mathrm{SrCu}_{2} \mathrm{O}_{2}$. J. Appl. Phys. 2002, 91, 3074-3078. [CrossRef]

164. Kudo, A.; Yanagi, H.; Ueda, K.; Hosono, H.; Kawazoe, H.; Yano, Y. Fabrication of transparent p-n heterojunction thin film diodes based entirely on oxide semiconductors. Appl. Phys. Lett. 1999, 75, 2851-2853. [CrossRef]

165. Ohta, H.; Kawamura, K.; Orita, M.; Sarukura, N.; Hirano, M.; Hosono, H. UV-emitting diode composed of transparent oxide semiconductors: p-SrCu $\mathrm{O}_{2} / \mathrm{n}-\mathrm{ZnO}$. Electron. Lett 2000, 36, 984-985. [CrossRef]

166. Hosono, H.; Ohta, H.; Hayashi, K.; Orita, M.; Hirano, M. Near-UV emitting diodes based on a transparent p-n junction composed of heteroepitaxially grown p- $\mathrm{SrCu}_{2} \mathrm{O}_{2}$ and n-ZnO. J. Cryst. Growth 2002, 237, 496-502. [CrossRef]

167. Inoue, S.-I.; Ueda, K.; Hosono, H.; Hamada, N. Electronic structure of the transparent p-type semiconductor (LaO)CuS. Phys. Rev. B 2001, 64, 245211. [CrossRef]

168. Ueda, K.; Inoue, S.; Hirose, S.; Kawazoe, H.; Hosono, H. Transparent p-type semiconductor: Lacuos layered oxysulfide. Appl. Phys. Lett. 2000, 77, 2701-2703. [CrossRef]

169. Hiramatsu, H.; Ueda, K.; Ohta, H.; Orita, M.; Hirano, M.; Hosono, H. Preparation of transparent p-type $\left(\mathrm{La}_{1-x} \mathrm{Sr}_{x} \mathrm{O}\right)$ cus thin films by RF sputtering technique. Thin Solid Films 2002, 411, 125-128. [CrossRef] 
170. Hiramatsu, H.; Ueda, K.; Takafuji, K.; Ohta, H.; Hirano, M.; Kamiyama, T.; Hosono, H. Intrinsic excitonic photoluminescence and band-gap engineering of wide-gap p-type oxychalcogenide epitaxial films of LnCuOCh (Ln = La, Pr, and Nd; Ch = S or Se) semiconductor alloys. J. Appl. Phys. 2003, 94, 5805-5808. [CrossRef]

171. Ueda, K.; Hosono, H.; Hamada, N. Energy band structure of $\mathrm{LnCuOCh}(\mathrm{Ch}=\mathrm{S}$, Se and Te) calculated by the full-potential linearized augmented plane-wave method. J. Phys. Condens. Matter 2004, 16, 5179. [CrossRef]

172. Liu, M.-L.; Wu, L.-B.; Huang, F.-Q.; Chen, L.-D.; Chen, I.-W. A promising p-type transparent conducting material: Layered oxysulfide $\left[\mathrm{Cu}_{2} \mathrm{~S}_{2}\right]\left[\mathrm{Sr}_{3} \mathrm{Sc}_{2} \mathrm{O}_{5}\right]$. AIP J. Appl. Phys. 2007, 102, 116108. [CrossRef]

173. Scanlon, D.O.; Buckeridge, J.; Catlow, C.R.A.; Watson, G.W. Understanding doping anomalies in degenerate p-type semiconductor lacuose. J. Mater. Chem. C 2014, 2, 3429-3438. [CrossRef]

174. Ueda, K.; Takafuji, K.; Hiramatsu, H.; Ohta, H.; Kamiya, T.; Hirano, M.; Hosono, H. Electrical and optical properties and electronic structures of $\operatorname{LnCuOS}(\mathrm{Ln}=\mathrm{La} \sim \mathrm{Nd})$. Chem. Mater. 2003, 15, 3692-3695. [CrossRef]

175. Hiramatsu, H.; Ueda, K.; Ohta, H.; Hirano, M.; Kamiya, T.; Hosono, H. Degenerate p-type conductivity in wide-gap $\mathrm{LaCuOS}_{1-x} \mathrm{Se}_{x}(x=0-1)$ epitaxial films. Appl. Phys. Lett. 2003, 82, 1048-1050. [CrossRef]

176. Hiramatsu, H.; Yanagi, H.; Kamiya, T.; Ueda, K.; Hirano, M.; Hosono, H. Crystal structures, optoelectronic properties, and electronic structures of layered oxychalcogenides $\mathrm{MCuOCh}(\mathrm{M}=\mathrm{Bi}, \mathrm{La} ; \mathrm{Ch}=\mathrm{S}, \mathrm{Se}, \mathrm{Te})$ : Effects of electronic configurations of $\mathrm{M}^{3+}$ ions. Chem. Mater. 2007, 20, 326-334. [CrossRef]

177. Ueda, K.; Hosono, H.; Hamada, N. Valence-band structures of layered oxychalcogenides, $\mathrm{LaCuOCh}(\mathrm{Ch}=\mathrm{S}$, Se, and Te), studied by ultraviolet photoemission spectroscopy and energy-band calculations. J. Appl. Phys. 2005, 98, 043506. [CrossRef]

178. Ueda, K.; Takafuji, K.; Yanagi, H.; Kamiya, T.; Hosono, H.; Hiramatsu, H.; Hirano, M.; Hamada, N. Optoelectronic properties and electronic structure of YCuOSe. J. Appl. Phys. 2007, 102, 113714. [CrossRef]

179. Hiramatsu, H.; Orita, M.; Hirano, M.; Ueda, K.; Hosono, H. Electrical conductivity control in transparent p-type (LaO)CuS thin films prepared by rf sputtering. J. Appl. Phys. 2002, 91, 9177-9181. [CrossRef]

180. Ueda, K.; Hosono, H. Band gap engineering, band edge emission, and p-type conductivity in wide-gap $\mathrm{LaCuOS}_{1-x} \mathrm{Se}_{x}$ oxychalcogenides. J. Appl. Phys. 2002, 91, 4768-4770. [CrossRef]

181. Hiramatsu, H.; Ueda, K.; Ohta, H.; Orita, M.; Hirano, M.; Hosono, H. Heteroepitaxial growth of a wide-gap p-type semiconductor, LaCuOS. Appl. Phys. Lett. 2002, 81, 598-600. [CrossRef]

182. Hamberg, I.; Granqvist, C.G. Evaporated Sn-doped $\mathrm{In}_{2} \mathrm{O}_{3}$ films: Basic optical properties and applications to energy-efficient windows. J. Appl. Phys. 1986, 60, R123-R160. [CrossRef]

183. Slaoui, A.; Siffert, P. Determination of the electron effective mass and relaxation time in heavily doped silicon. Phys. Status Solidi (a) 1985, 89, 617-622. [CrossRef]

184. Hosono, H. Built-in nanostructures in transparent oxides for novel photonic and electronic functions materials. Int. J. Appl. Ceram. Technol. 2004, 1, 106-118. [CrossRef]

185. Moss, T. The interpretation of the properties of indium antimonide. Proc. Phys. Soc. Sect. B 1954, $67,775$. [CrossRef]

186. Goto, Y.; Tanaki, M.; Okusa, Y.; Shibuya, T.; Yasuoka, K.; Matoba, M.; Kamihara, Y. Effects of the Cu off-stoichiometry on transport properties of wide gap p-type semiconductor, layered oxysulfide lacuso. Appl. Phys. Lett. 2014, 105, 022104. [CrossRef]

187. Hiramatsu, H.; Ueda, K.; Ohta, H.; Kamiya, T.; Hirano, M.; Hosono, H. Excitonic blue luminescence from $\mathrm{p}-\mathrm{LaCuOSe} / \mathrm{n}-\mathrm{InGaZn}_{5} \mathrm{O}_{8}$ light-emitting diode at room temperature. Appl. Phys. Lett. 2005, 87, 211107. [CrossRef]

188. Yanagi, H.; Kikuchi, M.; Kim, K.-B.; Hiramatsu, H.; Kamiya, T.; Hirano, M.; Hosono, H. Low and small resistance hole-injection barrier for NPB realized by wide-gap p-type degenerate semiconductor, LaCuOSe:Mg. Org. Electron. 2008, 9, 890-894. [CrossRef]

189. Zhang, N.; Liu, X.; Shi, D.; Tang, B.; Annadi, A.; Gong, H. Achievement of highly conductive p-type transparent ndcuos film with cu deficiency and effective doping. Mater. Today Chem. 2018, 10, 79-89. [CrossRef]

190. Kremers, H.; Stevens, R. Observations on the rare earths. XIV. The preparation and properties of metallic lanthanum. J. Am. Chem. Soc. 1923, 45, 614-617. [CrossRef]

191. Nakachi, Y.; Ueda, K. Single crystal growth of lacuos by the flux method. J. Cryst. Growth 2008, 311, 114-117. [CrossRef] 
192. Doussier-Brochard, C.; Chavillon, B.; Cario, L.; Jobic, S. Synthesis of p-type transparent LaOCuS nanoparticles via soft chemistry. Inorg. Chem. 2010, 49, 3074-3076. [CrossRef] [PubMed]

193. Lian, J.; Li, N.; Wang, H.; Su, Y.; Zhang, G.; Liu, F. Synthesis of lacuos nanopowder by a novel precipitation combined with reduction route. Ceram. Int. 2016, 42, 11473-11477. [CrossRef]

194. Zhang, N.; Gong, H. p-type transparent lacuos semiconductor synthesized via a novel two-step solid state reaction and sulfurization process. Ceram. Int. 2017, 43, 6295-6302. [CrossRef]

195. Hiramatsu, H.; Ueda, K.; Ohta, H.; Hirano, M.; Kamiya, T.; Hosono, H. Wide gap p-type degenerate semiconductor: Mg-doped LaCuOSe. Thin Solid Films 2003, 445, 304-308. [CrossRef]

196. Zhang, N.; Shi, D.; Liu, X.; Annadi, A.; Tang, B.; Huang, T.J.; Gong, H. High performance p-type transparent LaCuOS thin film fabricated through a hydrogen-free method. Appl. Mater. Today 2018, 13, 15-23. [CrossRef]

197. Wang, Z.; Nayak, P.K.; Caraveo-Frescas, J.A.; Alshareef, H.N. Recent developments in p-type oxide semiconductor materials and devices. Adv. Mater. 2016, 28, 3831-3892. [CrossRef] [PubMed]

198. Xu, W.; Li, H.; Xu, J.-B.; Wang, L. Recent advances of solution-processed metal oxide thin-film transistors. ACS Appl. Mater. Interfaces 2018, 10, 25878-25901. [CrossRef]

199. Nolan, M.; Elliott, S.D. The p-type conduction mechanism in $\mathrm{Cu}_{2} \mathrm{O}$ : A first principles study. Phys. Chem. Chem. Phys. 2006, 8, 5350-5358. [CrossRef]

200. Fortunato, E.; Figueiredo, V.; Barquinha, P.; Elamurugu, E.; Barros, R.; Gonçalves, G.; Park, S.-H.K.; Hwang, C.-S.; Martins, R. Thin-film transistors based on p-type $\mathrm{Cu}_{2} \mathrm{O}$ thin films produced at room temperature. Appl. Phys. Lett. 2010, 96, 192102. [CrossRef]

201. Saji, K.J.; Populoh, S.; Tiwari, A.N.; Romanyuk, Y.E. Design of p-CuO/n-ZnO heterojunctions by rf magnetron sputtering. Phys. Status Solidi (a) 2013, 210, 1386-1391. [CrossRef]

202. Chen, W.-C.; Hsu, P.-C.; Chien, C.-W.; Chang, K.-M.; Hsu, C.-J.; Chang, C.-H.; Lee, W.-K.; Chou, W.-F.; Hsieh, H.-H.; Wu, C.-C. Room-temperature-processed flexible $\mathrm{n}-\mathrm{InGaZnO} / \mathrm{p}-\mathrm{Cu}_{2} \mathrm{O}$ heterojunction diodes and high-frequency diode rectifiers. J. Phys. D Appl. Phys. 2014, 47, 365101. [CrossRef]

203. Dhakal, D.; Waechtler, T.; Schulz, S.E.; Gessner, T.; Lang, H.; Mothes, R.; Tuchscherer, A. Surface chemistry of a $\mathrm{Cu}(\mathrm{I})$ beta-diketonate precursor and the atomic layer deposition of $\mathrm{Cu}_{2} \mathrm{O}$ on $\mathrm{SiO}_{2}$ studied by X-ray photoelectron spectroscopy. J. Vac. Sci. Technol. A 2014, 32, 041505. [CrossRef]

204. Kwon, J.-D.; Kwon, S.-H.; Jung, T.-H.; Nam, K.-S.; Chung, K.-B.; Kim, D.-H.; Park, J.-S. Controlled growth and properties of p-type cuprous oxide films by plasma-enhanced atomic layer deposition at low temperature. Appl. Surf. Sci. 2013, 285, 373-379. [CrossRef]

205. Lee, S.W.; Lee, Y.S.; Heo, J.; Siah, S.C.; Chua, D.; Brandt, R.E.; Kim, S.B.; Mailoa, J.P.; Buonassisi, T.; Gordon, R.G. Improved $\mathrm{Cu}_{2} \mathrm{O}$-based solar cells using atomic layer deposition to control the $\mathrm{Cu}$ oxidation state at the p-n junction. Adv. Energy Mater. 2014, 4, 1301916. [CrossRef]

206. Chen, A.; Long, H.; Li, X.; Li, Y.; Yang, G.; Lu, P. Controlled growth and characteristics of single-phase $\mathrm{Cu}_{2} \mathrm{O}$ and Cuo films by pulsed laser deposition. Vacuum 2009, 83, 927-930. [CrossRef]

207. Tanaka, H.; Shimakawa, T.; Miyata, T.; Sato, H.; Minami, T. Electrical and optical properties of TCO-Cu $2 \mathrm{O}$ heterojunction devices. Thin Solid Films 2004, 469, 80-85. [CrossRef]

208. Kikuchi, N.; Tonooka, K. Electrical and structural properties of Ni-doped $\mathrm{Cu}_{2} \mathrm{O}$ films prepared by pulsed laser deposition. Thin Solid Films 2005, 486, 33-37. [CrossRef]

209. Zou, X.; Fang, G.; Yuan, L.; Li, M.; Guan, W.; Zhao, X. Top-gate low-threshold voltage p-Cu ${ }_{2} \mathrm{O}$ thin-film transistor grown on $\mathrm{SiO}_{2} / \mathrm{Si}$ substrate using a high-k HfON gate dielectric. IEEE Electron Device Lett. 2010, 31, 827-829. [CrossRef]

210. Jeong, S.; Aydil, E.S. Structural and electrical properties of $\mathrm{Cu}_{2} \mathrm{O}$ thin films deposited on $\mathrm{ZnO}$ by metal organic chemical vapor deposition. J. Vac. Sci. Technol. A 2010, 28, 1338-1343. [CrossRef]

211. Park, I.-J.; Jeong, C.-Y.; Myeonghun, U.; Song, S.-H.; Cho, I.-T.; Lee, J.-H.; Cho, E.-S.; Kwon, H.-I. Bias-stress-induced instabilities in p-type $\mathrm{Cu}_{2} \mathrm{O}$ thin-film transistors. IEEE Electron Device Lett. 2013, 34, 647-649. [CrossRef]

212. Nie, S.; Sun, J.; Gong, H.; Chen, Z.; Huang, Y.; Xu, J.; Zhao, L.; Zhou, W.; Wang, Q. Glucose-assisted reduction achieved transparent p-type cuprous oxide thin film by a solution method. EPL (Eur. Lett.) 2016, 115, 37005. [CrossRef]

213. Kim, S.Y.; Ahn, C.H.; Lee, J.H.; Kwon, Y.H.; Hwang, S.; Lee, J.Y.; Cho, H.K. p-Channel oxide thin film transistors using solution-processed copper oxide. ACS Appl. Mater. Interfaces 2013, 5, 2417-2421. [CrossRef] [PubMed] 
214. Yu, W.; Han, M.; Jiang, K.; Duan, Z.; Li, Y.; Hu, Z.; Chu, J. Enhanced fröhlich interaction of semiconductor cuprous oxide films determined by temperature-dependent raman scattering and spectral transmittance. J. Raman Spectrosc. 2013, 44, 142-146. [CrossRef]

215. Matsuzaki, K.; Nomura, K.; Yanagi, H.; Kamiya, T.; Hirano, M.; Hosono, H. Epitaxial growth of high mobility $\mathrm{Cu}_{2} \mathrm{O}$ thin films and application to p-channel thin film transistor. Appl. Phys. Lett. 2008, 93, 202107. [CrossRef]

216. Yao, Z.; Liu, S.; Zhang, L.; He, B.; Kumar, A.; Jiang, X.; Zhang, W.; Shao, G. Room temperature fabrication of p-channel $\mathrm{Cu}_{2} \mathrm{O}$ thin-film transistors on flexible polyethylene terephthalate substrates. Appl. Phys. Lett. 2012, 101, 042114. [CrossRef]

217. Pattanasattayavong, P.; Thomas, S.; Adamopoulos, G.; McLachlan, M.A.; Anthopoulos, T.D. p-Channel thin-film transistors based on spray-coated $\mathrm{Cu}_{2} \mathrm{O}$ films. Appl. Phys. Lett. 2013, 102, 163505. [CrossRef]

218. Liu, A.; Liu, G.; Zhu, H.; Song, H.; Shin, B.; Fortunato, E.; Martins, R.; Shan, F. Water-induced scandium oxide dielectric for low-operating voltage n-and p-type metal-oxide thin-film transistors. Adv. Funct. Mater. 2015, 25, 7180-7188. [CrossRef]

219. Liu, A.; Nie, S.; Liu, G.; Zhu, H.; Zhu, C.; Shin, B.; Fortunato, E.; Martins, R.; Shan, F. In situ one-step synthesis of p-type copper oxide for low-temperature, solution-processed thin-film transistors. J. Mater. Chem. C 2017, 5, 2524-2530. [CrossRef]

(C) 2019 by the authors. Licensee MDPI, Basel, Switzerland. This article is an open access article distributed under the terms and conditions of the Creative Commons Attribution (CC BY) license (http://creativecommons.org/licenses/by/4.0/). 